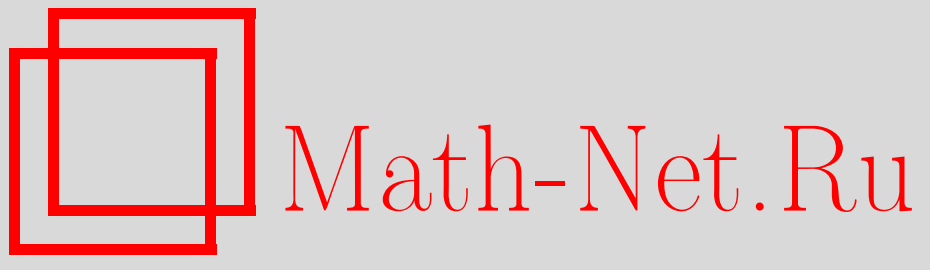

В. М. Золотарев, В. Ю. Королев, ХХ Международный семинар по проблемам устойчивости стохастических моделей (тезисы докладов) I, Теория вероятн. и ее примен., 2000, том 45, выпуск 4, 793-818

DOI: https://doi.org/10.4213/tvp513

Использование Общероссийского математического портала Math-Net.Ru подразумевает, что вы прочитали и согласны с пользовательским соглашением http://www . mathnet.ru/rus/agreement

Параметры загрузки:

IP: 54.224 .135 .184

26 апреля 2023 г., 12:44:12

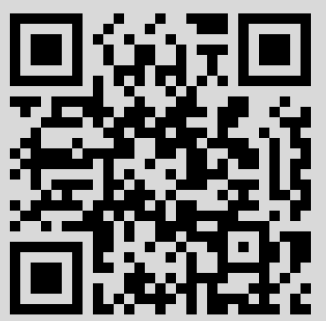




\section{ХХ МЕЖДУНАРОДНЫЙ СЕМИНАР ПО ПРОБЛЕМАМ УСТОЙЧИВОСТИ СТОХАСТИЧЕСКИХ МОДЕЛЕЙ}

ХХ Международный семинар по проблемам устойчивости стохастических моделей состоялся в маленьком курортном городе Наленчове близ Люблина, Польша, с 6 по 11 сентября 1999 г. Семинар был организован на базе университета им. Марии Склодовской-Кюри (Люблин) и Института математики Польской академии наук. В его работе приняли участие около двухсот специалистов из Австралии, Австрии, Алжира, Бельгии, Великобритании, Венгрии, Германии, Голландии, Дании, Иордании, Ирана, Италии, Канады, Литвы, Мексики, Польши, России, США, Тайваня, Турции, Украины, Швейцарии и Японии. Помимо тем, традиционно обсуждаемых на международных семинарах по проблемам устойчивости стохастических моделей, на этом семинаре работала отдельная секция, посвяценная квантовой теории вероятностей. Тематику семинара прекрасно отражает список пленарных докладов:

L. Accardi (Roma, Italy) «Quantum probability as a new frontier of classical probability»; families»:

A. Balkema (Amsterdam, The Netherlands) «Limit laws for multivariate exponential

V.E. Bening, V. Yu. Korolev (Moscow, Russia) «Nonparametric estimation of ruin probability for generalized risk processes»;

A. M. Chebotarev (Moscow, Russia) «On Markov evolution equation in quotient probability space»;

M. Csörgö (Carleton, Canada) «Random walking around financial mathematics»;

H. Fellag, M. Ibazizen (Tizi-Ouzou, Algeria) «Stability of the bias of the AR(1) model with contaminated exponential white noise»;

K. Głowacka, R. Zieliński (Warsaw, Poland) «A modification of the Famma-Roll estimator of the characteristic exponent»;

R.L. Hudson (Nottingham, Great Britain) «Some classical stochastic processes determined by quantum stochastic calculus»;

V. Kalashnikov, F. Enikeeva (Moscow, Russia), D. Rusaityte (Copenhagen, Denmark) «Continuity of ruin probabilities»;

W. A. Majewski (Gdańsk, Poland) «On noncommutative Liouville space technique»;

E. Omey (Brussels, Belgium) «The rate of convergence for subexponential distributions and densities»;

M. Riedel, H.-J. Rossberg (Leipzig, Germany) «Limit theorems for positive definite densities and their distributions》;

J. L. Teugels (Heverlee, Belgium) «Regular variation in risk theory».

Ниже публикуются резюме некоторых из этих и других сообщений участников семинара. Мы приносим извинения тем участникам семинара, чьи резюме докладов не могут быть представлены здесь в силу ограниченности объема журнала. Труды семинара полностью публикуются в трех выпусках «Journal of Mathematical Sciences».

Следуюший, XXI Международный семинар по проблемам устойчивости стохастических моделей состоится с 28 января по 3 февраля 2001 года в Эгере, Венгрия.

B. M. Зonomapes, В. Ю. Королев

* В этом номере мы публикуем первую часть реэюме докладов. Остальные резюме будут опубликованы в журнале «Теория вероятностей и ее применения» т. 46, в. 1. 
Balkema A. (Amsterdam, the Netherlands), Klüppelberg C. (Mainz, Germany), Resnick S. (Ithaca, USA) Stability for multivariate exponential families.

In the past decade there has been increased interest in the theory of multivariate exponential families and their asymptotic behavior on the one hand and exponential families which are invariant under a group of affine transformations on the other. This paper links these theories. If the vectors $X^{\lambda}$ of an exponential family can be normalized to converge to a nondegenerate limit vector $Y$, then the exponential family generated by the limit is stable in the sense that all vectors $Y^{\gamma}$ in the limit exponential family are of the same type. A similar phenomenon occurs in the classical limit theory for sums of independent identically distributed random variables where the limit variable $Y$ is stable in the sense that all variables in the Lévy process are of the same type. In the univariate theory the similarity between the asymptotic theory of exponential families and the limit theory for sums is very close, see [1].

In the multivariate case a complete description of the stable exponential families is not available. Recent work of Faraut and Korányi on the theory of symmetric cones suggests that the classification problem may be difficult.

Let $X$ be a vector in the Euclidean space $\mathbf{E}$ with a moment generating function (m.g.f.) $K(\lambda)=\mathbf{E} e^{\lambda X}$. The domain of $K$ is the set $\Lambda=\{K<\infty\}$. The vector $X$ generates a natural exponential family of random vectors $X^{\lambda}$ with m.g.f. $K_{\lambda}(\xi)=K(\lambda+$ $\xi) / K(\lambda), \lambda \in \Lambda$. We make two assumptions: The vector $X$ is nondegenerate and the domain $\Lambda$ is open. This paper addresses the problem whether the random vectors $X^{\lambda}$ can be normalized to converge in law to a nondegenerate random vector $Y$.

Affine transformations $\alpha(x)=A x+a$ form a group $\mathscr{A}$. Two nondegenerate random vectors $X$ and $U$ on $\mathbf{E}$ are of the same type if there is an $\alpha \in \mathscr{A}$ such that $\alpha(X)$ and $U$ have the same distribution. The natural exponential family $X^{\lambda}, \lambda \in \Lambda$, is stable if $\Lambda$ is open and if the vectors $X^{\lambda}, \lambda \in \Lambda$, are of the same type. The set of all $\alpha \in \mathscr{A}$ such that $\alpha(X)$ is distributed like $X^{\lambda}$ for some $\lambda \in \Lambda$ is a closed group $\mathscr{G}$, the symmetry group of the family. Write $f(\lambda) \rightarrow a$ for $\lambda \rightarrow \partial$ if for any $\varepsilon>0$ there is a compact subset $A \subset \Lambda$ such that $d(f(\lambda), a)<\varepsilon$ for $\lambda \in \Lambda \sigma A$.

Theorem 1. Let $X^{\lambda}, \lambda \in \Lambda$, be the natural exponential family generated by the random vector $X$ on $\mathbf{E}$. Assume that the two conditions above hold. Let $Y$ be a nondegenerate vector and $\alpha: \Lambda \rightarrow \mathcal{A}$ continuous so that $Y_{\lambda}:=\alpha_{\lambda}^{-1}\left(X^{\lambda}\right) \Rightarrow Y$ for $\lambda \rightarrow \partial$. Then the natural exponential family generated by $Y$ is stable.

Corollary. The m.g.f. of $Y_{\lambda}$ converges to the m.g.f. of $Y$ for $\lambda \rightarrow \partial$.

Example A. The uniform distribution on the unit ball. Suppose $Z=(X, Y)$ in $\mathbf{R}^{d} \times \mathbf{R}$ is uniformly distributed on the open ball $D$ of radius one centered in $(0,1)$. Let $\lambda=(0,-\tau), \tau \rightarrow \infty$. The density of $Z^{\lambda}$ concentrates around the origin. In order to obtain a nondegenerate limit we blow up the ball to an ellipsoid centered in $(0, \tau)$ with semi-axes of length $\tau$ and $\sqrt{\tau}$. The limit of the ellipsoids as $\tau \rightarrow \infty$ is the paraboloid $Q=\{t>0\}$ with $t=y-x^{2} / 2$. The limit vector has density $\propto e^{-y}$ on $Q$ and yields a stable exponential family with domain $\Gamma=\mathbf{R}^{d} \times(-\infty, 0)$ and symmetry group $\mathscr{G}$ generated by $\left(x+p, y+p x+p^{2} / 2\right)$ and $\left(r x, r^{2} y\right)$.

Proposition 1. Let $Q, t$, and $\mathcal{G}$ be as above. For $s>0$, let $Z_{s}$ have the density

$$
g_{s}(x, y)=\frac{t^{s-1} e^{-y} 1_{Q}(x, y)}{(2 \pi)^{d / 2}} \Gamma(s)
$$

and for $s=0$ let $Z_{0}$ be the vector $\left(X_{0}, Y_{0}\right)$, where $X_{0}$ has a standard normal distribution on $\mathbf{R}^{d}$ and $Y_{0}=X_{0}^{2} / 2$. Each vector $Z_{s}, s \geqslant 0$, generates a stable exponential family $Z_{s}^{\lambda}$, $\lambda \in \Lambda=\mathbf{R}^{d} \times(-\infty,-1)$ with symmetry group $\mathcal{G}$ which lives on $Q$ or on $\partial Q$.

What can one say about the domains of attraction? For simplicity we consider the case of the unit disk in $\mathbf{R}^{d}$ though the results remain valid for certain convex bodies in $\mathbf{R}^{d+1}$. The domain of attraction is determined by a metric on $D$ akin to the hyperbolic metric. A $C^{-1}$-function $h=e^{\eta}$ on $D$ is called flat if in terms of polar coordinates $(r, \theta)$

$$
t\left(\frac{\partial \eta}{\partial r}\right) \rightarrow 0, \quad \sqrt{t}\left(\frac{\partial \eta}{\partial \theta}\right) \rightarrow 0, \quad t=1-r \rightarrow 0 .
$$


If $h$ is flat, then the vector with density $h t^{s-1}$ is attracted to $Z_{s}$ for $s>0$. Flat functions are less flat than they seem. One can construct a flat $C^{1}$-function $h$ on the open disk $D$ which has the following property: For each constant $c \in \mathbf{R}$ there exists a dense subset $D_{c}$ of directions $\theta$ in $[0,2 \pi]$ so that $f(r, \theta) \rightarrow c$ for $r \rightarrow 1$ if $\theta \in D_{c}$.

Example B. The Laplace distribution.

Proposition 2. For any $s>-(d+1) / 2$ the density

$$
g_{s}(x, y)=\frac{y^{s} e^{-\left(y+x^{2} / 2 y\right)}}{(2 \pi)^{d-1}} \Gamma\left(s+\frac{d+1}{2}\right)
$$

on $Q=\mathbf{R}^{d-1} \times(0, \infty)$ generates a stable exponential family.

The symmetry group $\mathscr{G}$ is generated by the linear maps $(x+p y, y)$ and $\left(r x, r^{2} y\right)$. The Laplace density $f \propto e^{-r}$ lies in the domain of attraction of $g_{1}$.

There is a certain duality between this example and the previous one. There the domain of attraction contained the uniform distributions on convex bodies with a $C^{2}$-boundary and a positive definite curvature. Here it contains the functions $e^{-\varphi} / c$, where $\varphi$ is a positively homogeneous convex function, and the domain of the m.g.f. is a convex body with a $C^{2}$-boundary and a positive definite curvature. In this case a $C^{1}$-function $h=e^{\eta}$ with $r(\partial \eta / \partial r) \rightarrow 0$ and $\sqrt{r}(\partial \eta / \partial \theta) \rightarrow 0$ as $r \rightarrow \infty$ is flat.

This family of stable exponential families and its domains of attraction has also been investigated by Nagaev and Zaigraev, see [2].

\section{REFERENCES}

1. Balkema A.A., Klüppelberg C., Resnick S.I. Limit laws for exponential families, Bernoulli, 1999, v. 5, p. 1-18.

2. Nagaev A., Zaigraev A. Abelian theorems for a class of probability distributions in $\mathbf{R}^{d}$ and their application, preprint, 1999.

Baran S. (Debrecen, Hungary) Asymptotic properties of an estimator in functional errors-in-variables models.

Consider the model

$$
\begin{aligned}
& y_{i}=g\left(\xi_{i}, \beta_{0}\right)+\delta_{i}, \\
& x_{i}=\xi_{i}+\varepsilon_{i},
\end{aligned}
$$

$i=1,2, \ldots$, where design points $\xi_{1}, \xi_{2}, \ldots$, are nonstochastic but not observed, $y_{i}, x_{i}$ are observed, $\varepsilon_{i}, \delta_{i}$ are (nonobserved, not necessarily independent) random error terms with zero expectation $(i=1,2, \ldots), \beta_{0}$ is the true value of the unknown parameter $\beta$ to be estimated.

Suppose that the parameter set is $p$-dimensional: $\beta_{0} \in \Theta \subset \mathbf{R}^{p} ; x_{i}, \xi_{i}, \varepsilon_{i}$ are $q$-dimensional vectors, $y_{i}, \delta_{i}$ are $r$-dimensional vectors $(i=1,2, \ldots), g: V \times \Theta \rightarrow \mathbf{R}^{r}$ is a known function, where $V \subseteq \mathbf{R}^{q}, \xi_{i} \in V$ for each $i$.

We shall suppose the existence of three sequences of auxiliary functions:

(Af) There exist an open set $U \supset \Theta$ and functions $f_{i} \in \mathrm{C}\left(\mathbf{R}^{q} \times U \rightarrow \mathbf{R}^{r}\right)$ such that $\mathbf{E} f_{i}\left(\xi+\varepsilon_{i}, \beta\right)=g(\xi, \beta)$ for each $\xi \in V, \beta \in \Theta, i \in \mathbf{N}$.

(Ah) There exist functions $h_{i} \in \mathbf{C}\left(\mathbf{R}^{q} \times U \rightarrow \mathbf{R}\right)$ such that $\mathbf{E} h_{i}\left(\xi+\varepsilon_{i}, \beta\right)=\|g(\xi, \beta)\|^{2}$ for each $\xi \in V, \beta \in \Theta, i \in \mathbf{N}$.

(Ad) There exist functions $d_{i} \in \mathrm{C}\left(\mathbf{R}^{q} \times U \rightarrow \mathbf{R}\right)$ such that $\mathbf{E} d_{i}\left(\xi+\varepsilon_{i}, \beta\right)=\mathbf{E} \delta_{i}^{\top} f_{i}(\xi+$ $\left.\varepsilon_{i}, \beta\right)$ for each $\xi \in V, \beta \in \Theta, i \in \mathbf{N}$.

Let the estimator $\widehat{\beta}_{n}$ of $\beta_{0}$ be the minimum point of

$$
Q_{n}(\beta)=\frac{1}{n} \sum_{i=1}^{n}\left\{\left\|y_{i}-f_{i}\left(x_{i}, \beta\right)\right\|^{2}+h_{i}\left(x_{i}, \beta\right)-\left\|f_{i}\left(x_{i}, \beta\right)\right\|^{2}+2 d_{i}\left(x_{i}, \beta\right)\right\} .
$$


The above estimator is a natural generalization of the estimators described in [4] and [5]. In the case when $g(x, \beta)=\beta_{0}+\beta_{1} x+\cdots+\beta_{k} x^{k}, x \in \mathbf{R}$, the system of equations

$$
\frac{\partial Q_{n}(\beta)}{\partial \beta_{j}}=0, \quad j=0,1, \ldots, k,
$$

that provides a necessary condition for a $\beta$ to be the minimum of $Q_{n}$ is exactly the same system of linear equations that gives the estimator of $\beta_{0}$ in [2].

To prove the consistency of the estimator $\widehat{\beta}_{n}$ we need some conditions that are listed below. Let $\varphi_{n}\left(x_{n}, \beta\right)$ denote $f_{n}\left(x_{n}, \beta\right), h_{n}\left(x_{n}, \beta\right), d_{n}\left(x_{n}, \beta\right)$, or $\delta_{n}^{\top} f_{n}\left(x_{n}, \beta\right)$.

(A1) For each sequence $\left\{\xi_{i}\right\}$ and for each $\beta^{*} \in \Theta$ and $b>0$

$$
\liminf _{n \rightarrow \infty} \inf _{\left\|\beta-\beta^{*}\right\| \geqslant b} \frac{1}{n} \sum_{i=1}^{n}\left\|g\left(\xi_{i}, \beta\right)-g\left(\xi_{i}, \beta^{*}\right)\right\|^{2}>0 .
$$

(A2) For each $b>0$ there exists $\ell>0$ such that for each $s \in V$

$$
\left\|g\left(s, \beta_{1}\right)-g\left(s, \beta_{2}\right)\right\|<b \quad \text { if }\left\|\beta_{1}-\beta_{2}\right\|<\ell .
$$

$$
\lim _{\ell \rightarrow 0} \limsup _{n \rightarrow \infty} \mathbf{E} \sup _{\left\|\beta_{1}-\beta_{2}\right\| \leqslant \ell}\left\|\varphi_{n}\left(x_{n}, \beta_{1}\right)-\varphi_{n}\left(x_{n}, \beta_{2}\right)\right\|=0 .
$$

We shall use mixing conditions for the dependence structure of $\left\{\delta_{i}, \varepsilon_{i}, i=1,2, \ldots\right\}$. The following condition will be appropriate for our purpose:

$$
b(\alpha, t, a)=\sum_{k=1}^{\infty} \alpha^{a /(j(t)+a)}(k)(k+1)^{j(t)-2}<\infty,
$$

where $a>0, j(t)=2 \min \{k \in \mathbf{N}: 2 k \geqslant t\}$, and $\alpha(n)$ is the mixing coefficient for strong mixing.

Now, let us formulate the theorem that concerns the consistency of $\widehat{\beta}_{n}$.

Theorem 1. Assume that for the model (1)-(2) conditions (Af), (Ah), (Ad), and (A1)-(A3) are satisfied. Moreover, assume that the parameter set $\Theta$ is compact, $g$ is bounded on $V \times \Theta$ and for some $1<t \leqslant 2$ and $a>0$, the random variables $\left(\delta_{i}, \varepsilon_{i}\right), i \in \mathbf{N}$, satisfy the mixing condition $(A \alpha)$ and $\sup _{n} \mathbf{E}\left\|\varphi_{n}\left(x_{n}, \beta\right)\right\|^{t+a}<\infty$ for each $\beta \in \Theta$. Then $\lim _{n \rightarrow \infty} \widehat{\beta}_{n}=\beta_{0}$ in probability.

The proof is based on the Rosenthal inequality [3] and on the uniform law of large numbers (see, e.g., [5]). A detailed proof can be found in [1].

To prove asymptotic normality we need some additional conditions.

(B1) $\varphi_{i}(\xi, \beta)$ is twice differentiable with respect to $\beta$ for each $i$ and each $\xi$.

(B2) The $(2+a)$ th absolute moments of $\partial \varphi_{i}\left(x_{i}, \beta_{0}\right) / \partial \beta$ are bounded with respect to $i$.

(B3) $\mathbf{E} \sup _{\beta}\left\|\partial \varphi_{i}\left(x_{i}, \beta\right) / \partial \beta\right\|<\infty, \mathbf{E} \sup _{\beta}\left\|\partial^{2} \varphi_{i}\left(x_{i}, \beta\right) / \partial \beta^{2}\right\|<\infty$ for each $i$.

(B4) $\mathbf{E}\left\|\partial^{2} \varphi_{i}\left(x_{i}, \beta\right) / \partial \beta^{2}\right\|^{1+a}<\infty$ for each $i$ and $\beta$.

$$
\lim _{\ell \rightarrow 0} \limsup _{n \rightarrow \infty} \mathbf{E}\left(\sup _{\left\|\beta_{1}-\beta_{2}\right\| \leqslant \ell}\left\|\frac{\partial^{2} \varphi_{n}\left(x_{n}, \beta_{1}\right)}{\partial \beta^{2}}-\frac{\partial^{2} \varphi_{n}\left(x_{n}, \beta_{2}\right)}{\partial \beta^{2}}\right\|\right)=0 .
$$

(B6) The function

$$
m_{n}(\beta)=\frac{1}{n} \sum_{i=1}^{n} \frac{\partial g\left(\xi_{i}, \beta\right)^{\top}}{\partial \beta} \frac{\partial g\left(\xi_{i}, \beta\right)}{\partial \beta}
$$

converges to $m_{\infty}(\beta)$ uniformly in $\beta$ and $m_{\infty}(\beta)$ is invertible and continuous at $\beta_{0}$. 
Theorem 2. Suppose that for the model (1)-(2) conditions (Af), (Ah), (Ad) are satisfied, $\Theta$ is compact and convex, $\beta_{0} \in \Theta^{\circ}$, and $g$ is bounded on $V \times \Theta$. In addition, assume that for some $a>0$ conditions (B1)-(B6) and $(A \alpha)$ with $t=2$ are satisfied and

$$
\lim _{n \rightarrow \infty} \frac{1}{n} \Sigma_{n}=\Sigma
$$

where $\Sigma_{n}=\operatorname{var}\left(\sum_{s=1}^{n} \eta_{s}\right), \Sigma$ is a positive definite matrix and

$$
\eta_{s}=\frac{\partial h_{s}\left(x_{s}, \beta_{0}\right)}{\partial \beta}-2 \frac{\partial f_{s}\left(x_{s}, \beta_{0}\right)}{\partial \beta}{ }^{\top}\left[g_{s}\left(x_{s}, \beta_{0}\right)+\delta_{s}\right]+2 \frac{\partial d_{s}\left(x_{s}, \beta_{0}\right)}{\partial \beta} .
$$

Then, if $\widehat{\beta}_{n}$ is consistent then it is asymptotically normal. in $[1]$

The proof is based on a CLT for mixing processes (see [6]). The details can be found

The work was supported by the Hungarian Ministry of Education under Grant No FKFP 0121/1999.

\section{REFERENCES}

1. Baran $S$. A consistent estimator in general functional errors-in-variables models, Technical Report № 99/4, Kossuth University, Debrecen, 1999.

2. Cheng C.-L., Schneeweiss $H$. Polynomial regression with errors in the variables, J. Roy. Statist. Soc. Ser. B, Stat. Methodol., 1998, v. 60, p. 189-199.

3. Doukhan P. Mixing. Properties and Examples. - Lecture Notes in Stat. 85. New York: Springer, 1994.

4. Fazekas I., Lauridsen J. Asymptotic properties in space and time of an estimator in nonlinear functional errors-in-variables models. - Random Oper. Stochastic Equations, 1999 , v. 7, № 4, p. 389-411.

5. Fazekas I., Kukush A. G. Asymptotic properties of an estimator in nonlinear functional errors-in-variables models with dependent error terms. - Comput. Math. Appl., 1997, v. 34, № 10, p. 23-39.

6. Herrndorf $N$. A functional central limit theorem for weakly dependent sequences of random variables. - Ann. Probab., 1984, v. 12, № 1, p. 144-153.

Benesch T. (Graz, Austria) Parameter estimation of Gaussian autoregressive mixture models.

- A finite discrete Markov chain consists of a finite set of states $\mathscr{S}=\left\{S_{1}, \ldots, S_{N}\right\}$ and is observed at discrete times $t=1,2, \ldots, T$. We use the variable $\xi_{t}$ as the state of the Markov chain at discrete time $t$. We say that $\left(\xi_{t}\right)_{1 \leqslant t \leqslant T}$ is a Markov chain if $\mathbf{P}\left\{\xi_{t+1}=S_{j} \mid\right.$ $\left.\xi_{t}=S_{i}, \xi_{t-1}, \ldots, \xi_{1}\right\}=\mathbf{P}\left\{\xi_{t+1}=S_{j} \mid \xi_{t}=S_{i}\right\}$ holds for all times and states. This equation is referred to as Markov property in the discrete time case. $a_{i j}(t, t+1):=$ $\mathbf{P}\left\{\xi_{t+1}=S_{j} \mid \xi_{t}=S_{i}\right\}$ is called the transition probabilities from state $S_{i}$ to $S_{j}$ at time $t$. If $a_{i j}(t, t+1)=a_{i j}$ for all $t$, i.e., the transition probabilities do not depend on $t$, we speak about a Markov chain with stationary transition probabilities. The probability distributions of such a Markov chain are completely determined from the transition matrix $A=\left(a_{i j}\right)_{i, j=1, \ldots, N}$ and the initial state probability vector $c=\left(c_{i}\right)_{i=1, \ldots, N}$, where $c_{i}:=$ $\mathbf{P}\left\{\xi_{1}=S_{i}\right\}$.

In a hidden Markov model, the state $\xi_{t}$ at time $t$ cannot be observed directly, but there exists a set of possible observations $\mathcal{V}=\left\{V_{1}, \ldots, V_{K}\right\}(K<N)$. The representation is, therefore, doubly stochastic. Denote by $\omega_{t}$ the observation at time $t$. Being in state $S_{i}$ at time $t$, an observation $V_{k}$ is made with the probability $b_{i k}:=\mathbf{P}\left\{\omega_{t}=V_{k} \mid \xi_{t}=S_{i}\right\}$. Thus, a hidden Markov model is described by $\mathscr{M}=(A, B, c)$, where $B=\left(b_{i k}\right)_{i=1, \ldots, N ; k=1, \ldots, K}$.

In continuous density hidden Markov models the discrete probability function $b_{i k}=$ $\mathbf{P}\left\{\omega_{t}=V_{k} \mid \xi_{t}=S_{i}\right\}$ of observing $V_{k}$ while being in state $S_{i}$ is replaced by the continuous density function $b_{i}(X)$, where $X$ is an element of the continuous observation set that is $d$-dimensional Euclidean. 
A continuous density hidden Markov model is described by $\mathscr{M}=(A, F, c)$, where $F=\left\{b_{i}(\cdot)\right\}$ denotes the set of density functions.

In autoregressive hidden Markov model we assume a white noise source with unity variance, i.e., $\sigma^{2}=1$, followed by an all-pole filter $1 / A(z)$, where $A(z)=1+a_{1} z^{-1}+$ $a_{2} z^{-2}+\cdots+a_{p} z^{-p}$.

If we denote the output of the white noise as $\varepsilon_{i}, i \in Z$, then $y_{k}=-\sum_{i=1}^{p} a_{i} y_{k-i}+\varepsilon_{k}$, i.e., $\left(y_{k}\right)_{k \in Z}$ is an autoregressive process of order $p$, with coefficients $\mathbf{a}=\left(a_{0}, a_{1}, \ldots, a_{p}\right)$, where $a_{0}$ is always the unity. The $a_{i}$ are called the autoregressive coefficients.

We want express the density function of the random vector $Y=\left(y_{1}, y_{2}, \ldots, y_{d}\right)$, i.e., $f(X)$, where $X=\left(x_{1}, x_{2}, \ldots, x_{d}\right)$ is an element of the continuous observation set that is $d$-dimensional Euclidean.

The paper [2] shows that for large $d$, the density function for $Y$ is approximately

$$
f(X)=(2 \pi)^{-d / 2} \exp \left\{-\frac{\delta(X ; \mathbf{a})}{2}\right\}
$$

where

$$
\begin{gathered}
\delta(X ; \mathbf{a})=r_{a}(0) r(0)+2 \sum_{i=1}^{p} r_{a}(i) r(i), \quad \mathbf{a}=\left[1, a_{1}, a_{2}, \ldots, a_{p}\right]^{\prime}, \\
r_{a}(i)=\sum_{n=0}^{p-i} a_{n} a_{n+1} \quad \text { with } a_{0}=1, \quad r(i)=\sum_{n=1}^{d-i} x_{n} x_{n+i}, \quad 1 \leqslant i \leqslant p .
\end{gathered}
$$

Note that $r_{a}$ 's are the autocorrelation of the autoregressive coefficients and $r$ 's are the autocorrelation of the (normalized) observation samples.

In Gaussian autoregressive mixture models, the observation density $b_{i}(X)$, for $i=$ $1,2, \ldots, N$, has the form $b_{i}(X)=\sum_{l=1}^{L} \gamma_{i l} f_{i l}(X)$, where $L$ is the number of mixture components, $\gamma_{i l}$ is the weight for the lth mixture component satisfies $\sum_{l=1}^{L} \gamma_{i l}=1$ and we use (1) as the basis density defined by an autoregression vector a or equivalently an autocorrelation vector $\mathbf{r}_{a}=\left[r_{a}(0), r_{a}(1), \ldots, r_{a}(p)\right]^{\prime}$ as $f_{i I}(X)=(2 \pi)^{-d / 2} \exp \left\{-\delta\left(X ; \mathbf{a}_{i l}\right) / 2\right\}$, where $a_{i l}$ is the parameter vector defining the density for the lth mixture component, all relates to state $S_{i}$.

By parameter estimation, we mean the problem of how to adjust the model parameters of $\mathscr{M}$ to maximize $\mathbf{P}\{\Omega \mid \mathscr{M}\}$. One reasonable solution for this problem is an iterative procedure to find a parameter set of $\mathscr{M}$, which locally maximizes $\mathbf{P}\{\Omega \mid \mathscr{M}\}$. Therefore, a variant of the Baum-Welch algorithm (see, for example, [1]) is used.

We define the state sequence $\Xi=\xi_{1} \xi_{2} \ldots \xi_{T}$ and the branch alphabet $\Omega_{b}:=$ $\{1,2, \ldots, L\} . \Omega_{b}^{T}$ is the set of all $T$-tuples $K=\left(k_{1}, k_{2}, \ldots, k_{T}\right)$, where every $k_{t} \in \Omega_{b} . K$ is called a branch sequence.

We define an auxiliary function, based on the Kullback-Leibler statistic,

$$
Q\left(\mathscr{M}, \mathscr{M}^{\prime}\right):=\sum_{\Xi} \sum_{K} f(\Omega, \Xi, K \mid \mathscr{M}) \ln f\left(\Omega, \Xi, K \mid \mathscr{M}^{\prime}\right),
$$

where $\mathscr{M}$ is the current model. The paper [1] shows that $Q\left(\mathscr{M}, \mathscr{M}^{\prime}\right) \geqslant Q(\mathscr{M}, \mathscr{M})$ implies $f\left(\Omega \mid \mathscr{M}^{\prime}\right) \geqslant f(\Omega \mid \mathscr{M})$.

Let $b_{i l}$ be the parameter set defining the density $f_{i l}(\cdot)$. We can separate the auxiliary function in terms dependent only from $A, c, \gamma_{i l}$, and $b_{i l}$. For the solution for $A, c$, and $\gamma_{i l}$ see, for example, [3].

For $a_{i l}$ we get $\delta\left(\bar{\omega}_{t} ; \mathbf{a}_{i l}^{\prime}\right)=\min _{\mathbf{a}} \delta\left(\bar{\omega}_{t} ; \mathbf{a}\right)$, where $\bar{\omega}_{t}$ represents a composite observation whose autocorrelation coefficients are $\bar{r}_{i l}(j)=\sum_{t=1}^{T} f\left(\Omega, \xi_{t}=S_{i}, k_{t}=l \mid \mathscr{M}\right) r_{t}(j)$ with $r_{t}(\cdot)$ the autocorrelation coefficient of the $t$ th observation vector, $\omega_{t}$, with the components $\omega_{t, j}, j=1,2, \ldots, d$, i.e., $r_{t}(i)=\sum_{j=1}^{d-i} \omega_{t, j} \omega_{i,(j+i)}$.

Therefore, from $\bar{r}_{i l}(j), j=0,1,2, \ldots, p$, one can solve a set of normal equations and obtain the corresponding autoregressive coefficient vector which is exactly the required $\mathbf{a}_{i l}^{\prime}$ vector in the Gaussian autoregressive density for the lth mixture component in the ith state. 


\section{REFERENCES}

1. Baum L.E., Petrie T., Soules G., Weiss N. A maximation technique occurring in the statistical analysis of probabilistic functions of Markov chains. - Ann. Math. Statist., 1970 , v. 41 , № 1, p. 164-171.

2. Juang B.-H. On the hidden Markov model and dynamic time warping for speech recognition - a unified view, AT\&T Bell Labs. - Tech. J., 1984, v. 63, № 7, p. 12131243.

3. Rabiner L. R. A tutorial on hidden Markov models. - In: Proceedings of the IEEE, 1989 , v. 77 , № 2, p. 257-286.

Бенинг В.Е. (Москва, Россия) Оченки скорости сходимости и асимптотические разложения при альтернативах.

В докладе рассматривается обобщение третьей леммы Ле Кама (см. [1, лемма 6.1 .4$, с. 263]), позволяюпее исследовать оценки скорости сходимости и асимптотические разложения при альтернативах для распределений статистик крнтериев.

Оценки скорости сходимости и асимптотические разложения при альтернативах для распределений статистик критериев $T_{n}=T_{n}\left(\mathbf{X}_{n}\right)$ важны с точки зрения свойств функций мощностей соответствующих критериев.

Во многих случаях распределения при альтернативах изучались теми же методами, что и при гипотезе. Например, пусть распределение исходных наблюдений $\mathbf{X}_{n}$ зависит от параметра $\theta$, а проверяется гипотеза $\mathbf{H}_{0}: \theta=\theta_{0}$. Предположим, что критерий основан на статистике $T_{n}$, являющейся асимптотически нормальной $c$ параметрами $\left(\mu_{n}(\theta), \sigma_{n}^{2}(\theta)\right)$. Тогда подстановка $\theta=\theta_{0}$ дает распределение при гипотезе $\mathbf{H}_{0}$, а подстановка $\theta \neq \theta_{0}-$ распределение при альтернативе $\mathbf{H}_{1}$. При локальных альтернативах $\theta_{n} \rightarrow \theta_{0}$ получаем, что распределение $T_{n}$ асимптотически нормально с параметрами $\left(\mu_{n}\left(\theta_{n}\right), \sigma_{n}^{2}\left(\theta_{n}\right)\right)$.

Этот прямой подход, однако, не учитывает специфики задачи, связанной с локальностью альтернатив и ведет к излишним условиям регулярности, накладываемым при справедливости альтернативных гипотез. Метод, адекватный постановке задачи, дает теория Ле Кама (см. [1, глава 6]), основанная на понятии контигуальности. В частности, если $\Lambda_{n}=\Lambda_{n}\left(\mathbf{X}_{n}\right)$ - логарифм отношения правдоподобия $\theta_{n}$ к $\theta_{0}$, а совместное распределение $\left(\Lambda_{n}, T_{n}\right)$ при $\theta=\theta_{0}$ имеет предел, то и распределение $\left(\Lambda_{n}, T_{n}\right)$ при $\theta=\theta_{n}$ имеет предел, который легко определяется: если предельные распределения имеют плотности $p_{0}(x, y)$ и $p_{1}(x, y)$, то $p_{1}(x, y)=e^{x} p_{0}(x, y)$. Одно из эффективных применений этого метода известно в случае ранговых статистик [1], поскольку распределение вектора рангов при альтернативах значительно сложнее, чем при гипотезе, что затрудняет применение прямого подхода (см., например, [3]).

Пусть $\mathbf{P}_{n}$ и $\mathbf{Q}_{n}$ - две последовательности вероятностных мер, определенных на измеримых пространствах $\left(\mathscr{X}_{n}, \mathscr{A}_{n}\right), n=1,2, \ldots$, с плотностями $p_{n}(x)$ и $q_{n}(x)$ относительно $\sigma$-конечной меры $\mu_{n}$.

Анализируя доказательство третьей леммы Ле Кама, несложно получить следующее утверждение:

Лемма. Предположик, ито существует дифференцируемая функиия $\Phi_{n}(u, v)$ makas, чmo $\iint e^{v} d \Phi_{n}(u, v)<\infty$. Тогда для любого $A>0$

$$
\begin{aligned}
\sup _{x}\left|\mathbf{Q}_{n}\left\{T_{n}\left(\mathbf{X}_{n}\right)<x\right\}-\int_{-\infty}^{x} \int e^{v} d \Phi_{n}(u, v)\right| \\
\leqslant \mathbf{Q}_{n}\left\{p_{n}\left(\mathbf{X}_{n}\right)=0\right\}+\mathbf{Q}_{n}\left\{\left|\Lambda_{n}\left(\mathbf{X}_{n}\right)\right| \geqslant A\right\} \\
\quad+2\left(e^{A}+1\right) \sup _{u, v}\left|F_{n}(u, v)-\Phi_{n}(u, v)\right|+\iint_{|v| \geqslant A} e^{v} d \Phi_{n}(u, v),
\end{aligned}
$$




$$
\begin{aligned}
& \text { ade } F_{n}(u, v)=\mathbf{P}_{n}\left\{T_{n}\left(\mathbf{X}_{n}\right)<u, \Lambda_{n}\left(\mathbf{X}_{n}\right)<v\right\}, \\
& \Lambda_{n}(x)= \begin{cases}\log \frac{q_{n}(x)}{p_{n}(x)}, & p_{n}(x)>0, \\
0, & q_{n}(x)=p_{n}(x)=0, \\
+\infty, & p_{n}(x)=0, \quad q_{n}(x)>0 .\end{cases}
\end{aligned}
$$

Обычно в качестве $\Phi_{n}(u, v)$ выступает либо предельный закон, либо асимптотическое разложение для распределения $\left(T_{n}, \Lambda_{n}\right)$ при гипотезе $\mathbf{H}_{n 0}$, согласно которой распределение наблюдений $\mathbf{X}_{n}$ есть $\mathbf{P}_{n}$.

Рассмотрены применения этой леммы для случаев, когда в качестве статистики $T_{n}$ выступаюо ранговые статистики, линейные комбинации порядковых статистик и $U$-статистики. При этом требуемые условия регулярности, накладываемые на распределения $T_{n}\left(\mathbf{X}_{n}\right)$ и $\Lambda_{n}\left(\mathbf{X}_{n}\right)$ при справедливости гипотезы $\mathbf{H}_{n 0}$, близки к весьма слабым условиям из работы [2].

Работа выполнена при финансовой поддержке РФФИ, проекты 99-01-00847, 97-01-00271 и РГНФ, проект 97-02-02235.

\section{СПИСОК ЛИТЕРАТУРЫ}

1. Гаек Я., Шидак 3. Теория ранговых критериев. М.: Наука, 1971, 375 с.

2. Chibisov D. M., van Zwet W.R. On the Edgeworth expansion for the logarithm of the likelihood ratio. - Теория вероятн. и ее примен., 1984, т. 29, в. 3, с. 417-439.

3. Albers W., Bickel P.J., van Zwet W.R. Asymptotic expansion for the power of distribution-free tests in the one-sample problem. - Ann. Statist., 1976, v. 4, № 1 , p. 108-156; Corrections, 1978, v. 6, № 5, p. 1170-1171.

Weron A., Weron R. (Wroclaw, Poland) CED model III: Scaling law for high-frequency financial data.

Typical data sets employed by economists do not exceed a few hundred or thousand observations per series. However, in the last decade data sets containing tick-by-tick observations have become available. The studies of these data have turned up new and interesting facts about the pricing of assets. For example, it has been recognized recently that financial markets display scaling properties ([1], [2]) similar to those of complex systems found in diverse areas of science.

In this paper we show that currency exchange (FX) rate returns satisfy scaling with an exponent significantly different from that of a random walk. But what is more important, we also show that the Conditionally Exponential Decay (CED) model [3], [4] can be used to solve a long standing problem in the analysis of intra-daily data [5], i.e., it can be used to identify the mathematical structure of the distributions of FX returns corresponding to the empirical scaling laws.

The CED model is based on asymptotic behavior of complex stochastic systems and current developments of chaos theory. In particular, it is consistent with the fractal and the heterogeneous market hypotheses [1], [5], [6] which emphasize the impact of information and investment horizons on the behavior of investors. The basic assumptions of these hypotheses are the following: the market is made up of many individuals with a large number of different investment horizons and is heterogeneous in the geographic location of the participants; information has a different impact on different investment horizons; prices reflect a combination of short-term technical trading and long-term fundamental valuation.

The CED model clarifies the ideas of the fractal and the heterogeneous market hypotheses and provides a rigorous mathematical framework for further analysis of financial complex processes. In this model ([2], [4]) each $i$ th investor is related to a cluster of agents acting simultaneously on common markets. The influence of this cluster of agents is of the type of short-range interactions and is reflected by a random risk-aversion factor $A_{i}$. Interactions of the long-range type are imposed on the $i$ th investor by the inter-cluster 
relationship manifested by random risk factors $B_{j}^{i}$ for all $j \neq i$. They reflect how fast the information flows to the $i$ th investor. These assumptions lead to the following CED probability density of returns

$$
f(r)=\alpha \lambda(\lambda r)^{\alpha-1}\left[1-\exp \left(-\frac{(\lambda r)^{-\alpha}}{k}\right)\right] \exp \left[-\frac{1}{k} \int_{0}^{k(\lambda r)^{\alpha}}\left(1-e^{-1 / s}\right) d s\right]
$$

for $r>0$, which exhibits the two power-laws property

$$
f(r)= \begin{cases}C_{1}(\lambda r)^{\alpha-1} & \text { for } 0<\lambda r \ll 1, \\ C_{2}(\lambda r)^{-\alpha / k-1} & \text { for } \lambda r \gg 1\end{cases}
$$

where $C_{1}=\alpha \lambda$ and $C_{2}$ is a function of all three CED parameters: $\alpha$ - the shape, $\lambda-$ the scale, and $k$ - a parameter that decides how fast the information flow is spread out in the market.

A statistical study of financial data from the fractal point of view is based on the analysis of time intervals $\Delta t$ of different sizes. A reasonable question to ask is: What is the relation between volatility and the size of time intervals? The answer to this question is the scaling law for volatility $([1],[4])$

$$
v\left(t_{i}\right) \equiv v\left(t_{i}, \Delta t, T\right) \equiv \frac{1}{n} \sum_{k=1}^{n}\left|x\left(t_{i-k}\right)-x\left(t_{i-k}-\Delta t\right)\right|=c(\Delta t)^{D},
$$

where $x(t)$ is the logarithmic price at time $t, c$ is an empirical constant and $D$ is the empirical drift exponent. In spite of its elementary nature, a scaling law study is immediately able to reject the Gaussian hypothesis and reveal an important property of financial time series. For the Gaussian case the above formula is true with a drift exponent of 0.5. We have analyzed a data set which was released by Olsen \& Associates for the HFDF-II conference. It included exchange rates of major currencies (USD/DEM, GBP/USD, USD/JPY, USD/CHF, AUD/USD, DEM/JPY, GBP/DEM, USD/FRF, CAD/USD, DEM/FRF, DEM/ITL, DEM/FIM) from January 1, 1996 to December 31, 1996. The data came in files where GMT time and FX rates were reported sequentially in 30 minute intervals, thus the number of data was 17520 for each exchange rate. From this data we calculated the empirical drift exponent for the analyzed data $(D)$ and the CED drift exponent and the difference (in percent) between these two exponents. We have clearly seen that for all FX rates the exponent $D$ was significantly smaller than 0.5 (it is between 0.3249 for DEM/FRF and 0.4835 for GBP/DEM). Moreover, the difference between $D$ and $D_{\text {CED }}$ was small $\left(-4.3 \% \leqslant\left(D_{\text {CED }}-D\right) / D \leqslant-0.2 \%\right)$, thus showing that the theoretical model fits the empirical data very well.

These studies demonstrate that, in principle, it is possible to estimate the empirical drift exponent $D$, see formula (3), of the scaling law reported in [1] from the CED approach. Thus we have shown that the CED model can be used to solve the problem of Guillaume et al. [5].

\section{REFERENCES}

1. Müller U. A., Dacorogna M. M., Olsen R. B., Pictet O. V., Schwarz M., Morgenegg C. Statistical study of foreign exchange rates. - J. Banking \& Finance, 1990, v. 14, p. 1189-1208.

2. Weron A., Mercik Sz., Weron R. Origins of the scaling behavior in the dynamics of financial data. - Phys. A, 1999, v. 264, p. 562-569.

3. Jurlewicz A., Weron A., Weron $K$. Asymptotic behavior of stochastic systems with conditionally exponential decay property. - Appl. Math., 1996, v. 23, p. 379-394.

4. Weron $R$., Weron $K$., Weron $A$. A conditionally exponential decay approach to scaling in finance. - Phys. A, 1999, v. 264, p. 551-561.

5. Guillaume D.M., Dacorogna M.M., Dave R.R., Müller U.A., Olsen R.B., Pictet $O$. $V$. From the bird's eye to the microscope: A survey of new stylized facts of the intra-daily foreign exchange markets. - Finance Stochast., 1997, v. 1, p. 95-129. 
6. Peters E. E. Fractal Market Analysis: Applying Chaos Theory to Investment and Economics. New York: Wiley, 1994.

\section{Weron K. (Wroclaw, Poland) CED model II: Application to relaxation phe- nomena.}

A special case of the CED (Conditionally Exponential Decay) system has been first introduced ([1], [2]) to express mathematically the idea of the correlated cluster dynamics accepted as a physical mechanism underlying the relaxation response of dielectric systems [3]. Empirical evidence (including data from dielectric, mechanical, and magnetic relaxation, from Nuclear magnetic resonance, dynamic light and quasielastic neutron scattering, and also from chemical reaction kinetics) shows that relaxation, i.e., timedependent change of macroscopic properties of physical systems evolving to equilibrium exhibits a great degree of universality observed in the asymptotic properties of the relaxation function $\varphi(t)$ :

$$
-\frac{d \varphi(t)}{d t} \propto \begin{cases}(A t)^{-n} & \text { for } A t \ll 1 \\ (A t)^{-m-1} & \text { for } A t \gg 1\end{cases}
$$

The parameters of the power laws $0<n, m \leqslant 1$ and $A>0$ are the characteristic material constants. Because of the wide occurrence of the two-power-law response (1), the relaxation phenomenon represents one of the most intensively studied topics in theoretical physics. The main question asked in this context is about the cause of this phenomenon.

It is well known [3], that every relaxation process results from an appropriate transitional configuration into a system, imposed by nonequilibrium constraints at time $t=0$, and is conditioned by specific interactions of different parts of the system. Both, the lifetime of the initial nonequilibrium state of the complex system and the interactions have, in general, random characteristics. The evolution toward equilibrium of the system of size $N$ is represented by $\varphi(t)$ defined ([1], [2]) as the survival probability of system's initial state

$$
\varphi(t)=\mathbf{P}\left\{A_{N} \min \left(\theta_{1 N}, \ldots, \theta_{N N}\right) \geqslant t\right\}
$$

where $A_{N}$ is a sequence of suitable normalizing constants and $\theta_{i N}, 1 \leqslant i \leqslant N$, is the lifetime of the $i$ th subsystem in its initial state. The nonnegative variables $\theta_{1 N}, \ldots, \theta_{N N}$ are assumed to form a sequence of independent and identically distributed random variables for each $N$.

In the framework of the correlated cluster approach, the probability of preservation of the initial state until a time instant $t$ for each subsystem must necessarily be conditioned by variates reflecting the influence of random intra- and inter-cluster dynamics [4]. To model the physical reality, the following microscopic property for the initial nonequilibrium state of each subsystem (in the system of size $N$ ) has been proposed ([1], [2]):

$$
\mathbf{P}\left\{\theta_{i N} \geqslant t \mid \beta_{i}=b, \tilde{\eta}_{i, N}=s\right\}=\exp \{-b \min (t, s)\} .
$$

The random relaxation rate $\beta_{i}$ in (3) reflects the intra-cluster dynamics, while $\tilde{\eta}_{i, N}=$ $a_{N} \max \left(\eta_{1}^{i}, \ldots, \eta_{i-1}^{i}, \eta_{i+1}^{i}, \ldots, \eta_{N}^{i}\right)$ is the stopping time representing the influence of the inter-cluster correlations ( $a_{N}$ is a sequence of suitable normalizing constants). The random variable $\eta_{j \neq i}^{i}$ denotes the time needed for the structural transformation of the $j$ th subsystem evolving to equilibrium. The above property determines the minimal probability of preservation of the initial state for an individual $i$ th subsystem until an infinitely long time. The nonnegative variables $\left\{\beta_{i}\right\}$ and $\left\{\eta_{j}^{i}\right\}_{j \neq i}$ are assumed to form independent sequences of i.i.d. random variables.

Let us note that defined by relation (3) variables $\theta_{1 N}, \ldots, \theta_{N N}$ form a CED system which is a special case of the general scheme introduced in [5]. Therefore, for large $N$, if $\varphi(\infty)=0$ is assumed, the relaxation function (2) fulfills the following relaxation equation

$$
\frac{d \varphi(t)}{d t}=-\alpha A(A t)^{\alpha-1}\left[1-\exp \left\{-\frac{1}{k(A t)^{\alpha}}\right\}\right] \varphi(t),
$$

where $0<\alpha \leqslant 1, A>0$, and $k>0$. The solution of (4) yields the demanded power-law properties (1) of the response function $-d \varphi(t) / d t$ with parameters $n=1-\alpha, m=\alpha / k$, and $k \geqslant \alpha$. 


\section{REFERENCES}

1. Weron K. A probabilistic mechanism hidden behind the universal power law for dielectric response: general relaxation equation. - J. Phys., 1991, v. 3, p. 9151-9162.

2. Weron K., Jurlewicz A. Two forms of self-similarity as a fundamental feature of the power-law dielectric response. - J. Phys. A, 1993, v. 26, p. 395-410.

3. Jonscher A.K. Dielectric Relaxation in Solids. London: Chelsea Dielectric Press, 1983; Universal Relaxation Law. London: Chelsea Dielectric Press, 1996.

4. Weron $K$., Kotulski $M$. On the equivalence of the parallel channel and the correlated cluster relaxation models. - J. Stat. Phys., 1997, v. 88, p. 1241-1256.

5. Jurlewicz A., Weron A., Weron K. Asymptotic behaviour of stochastic systems with conditionally exponential decay property. - Appl. Math., 1996, v. 23, p. 379-394.

Вильчевский Н.О., Шевляков Г.Л. (Санкт-Петербург, Россия) Использование обобшенных многочленов Бернштейна в задаче оценивания функции распределения.

В теории приближений функций широко используются многочлены Бернштейна

$$
B_{n}(f, x)=\sum_{i=0}^{n} f\left(\frac{i}{n}\right) C_{n}^{i} x^{i}(1-x)^{n-i},
$$

которые реализуют теорему Вейерштрасса о равномерном приближении непрерывной на интервале $[0,1]$ функции $f(x)$ многочленами.

Iростота и оптимальные свойства конструкции (1) сделали возможным применить ее для оценивания законов распределений и их характеристик (предложено нами в [1]), в частности для оценивания квантильной функции $Q(t)\left(Q=F^{-1}\right)$ по выборке $\left\{x_{i}\right\}_{1}^{n}$ из распределения $F$

$$
B_{n-1}(Q, t)=\sum_{i=0}^{n-1} x_{(i+1)} C_{n-1}^{i} t^{i}(1-t)^{n-1-i},
$$

где $x_{(i)}-i$-я порядковая статистика выборки.

Рассмотрим обобщение конструкции (1) в следующем виде [1]:

$$
B_{n}(\Phi, f, \psi, x)=\sum_{i=0}^{n} \Phi\left[f\left(\frac{i}{n}\right)\right] C_{n}^{i}[\psi(x)]^{i}[1-\psi(x)]^{n-i} .
$$

Очевидно, что при естественных ограничениях на вид функций $\Phi, f$ и $\psi$ обобщенные многочлены Бернштейна (3) сходятся $\mathrm{K} \Phi[f(\psi(x))]$ равномерно относительно $\psi(x)$. Представление (3) расширяет возможности применения классической конструкции (1).

Іри аппроксимации обобщенными многочленами Бернштейна функций от порядковых статистик справедлив следующий результат.

Теорема 1. Рассматривается аналог комструкиии (2) для оченивания функчий от порядковых статистик в виде следующего обобщенкого многочлена Бернитейма:

$$
B_{n-1}(\Phi, Q, H, x)=\sum_{i=0}^{n-1} \Phi\left[x_{(i+1)}\right] C_{n-1)}^{i}[H(x)]^{i}[1-H(x)]^{n-1-i},
$$

где $x_{(i)}, i=1, \ldots, n$, есть упорядочекная по возрастанию совокупность кезависимых случайных величия, распределенных по захону $F(x)$, а $H(x)$ - функция распределения некоторой случайной величины.

Пусть $\Phi, Q$ и $H$ - монотокные $u$ дважды непрерывно дифференцируемье функиии своих аргументов. Тогда для математического ожидания $B_{n-1}$

$$
I_{n-1}(\Phi, Q, H, x)=E_{F}\left[B_{n-1}(\Phi, Q, H, x)\right]
$$


при $0<\alpha \leq t=H(x) \leq \beta<1$ имеет место следующее асимптотическое представление:

$$
\begin{gathered}
I_{n-1}(\Phi, Q, H, x)=\Phi[Q(H(x))]+\frac{3}{4 n} \Phi[Q(H(x))]-\frac{1}{2(n-1)} \frac{\Phi[Q(H(x))]}{H(x)(1-H(x))} \\
+\frac{2}{(2 n-1)}[H(x)(1-H(x))]^{5 / 4} \frac{\partial^{2}}{\partial t^{2}}\left(\frac{\Phi[Q(t)]}{(t(1-t))^{1 / 4}}\right)_{t=H(x)}+O\left(\frac{1}{n^{2}}\right) .
\end{gathered}
$$

Свойства обобщенных многочленов Бернштейна (3) также могут быть использованы для построения оценок функции распределения. Отметим, что при $\Phi=f^{-1}$ из (3) следует тождество

$$
B_{n}\left(f^{-1}, f, \psi, x\right) \equiv \psi(x),
$$

откуда $B_{n}(\Phi, f, \psi, x) \rightarrow \psi(x)$ при $\Phi \rightarrow f^{-1}$.

Чтобы оценить функцию распределения положим в (4) $\Phi=Q^{-1}=F$ и $H=F$. Тогда из (5) получим $B_{n-1}\left(Q^{-1}, Q, F, x\right) \equiv F(x)$, откуда следует, что $B_{n-1}(\Phi, Q, F, x) \longrightarrow F(x)$ при $\Phi \rightarrow Q^{-1}$.

Последнее свойство используется для построения адаптивной по выборке оценки функции распределения:

$$
\widehat{F}_{n+1}(x)=\sum_{i=0}^{n+1} \widehat{Q}_{n}^{-1}\left(x_{(i+1)}\right) C_{n+1)}^{i}\left[\widehat{F}_{n}(x)\right]^{i}\left[1-\widehat{F}_{n}(x)\right]^{n+1-i}
$$

где $n \geq n_{0}, \widehat{F}_{n}(x)=\widehat{Q}_{n}^{-1}(t)$, а начальное приближение берется в виде (2)

$$
\widehat{Q}_{n_{0}}(t)=\sum_{i=0}^{n_{0}} x_{(i+1)} C_{n_{0}}^{i} t^{i}(1-t)^{n_{0}-i}, \quad n_{0} \geqslant 2,0 \leqslant t \leqslant 1 .
$$

\section{СПИСОК ЛИТЕРАТУРЫ}

1. Вильчевский Н. О., ШІевляхов Г.Л. Применение полиномов Бернштейна в задачах адаптивного оценивания. - Материалы V Всесоюзной шиолы-семинара по непараметрическим и робастным методам статистики. Часть 1, Томск, 1985, c. $44-47$.

Gajowiak I., Rychlik Z. (Lublin, Poland) Weak convergence of randomly indexed sequences of random variables.

Let $\left\{Y_{n} n \geqslant 1\right\}$ be a sequence of random variables defined on a probability space $(\Omega, \mathscr{A}, P)$. Assume $Y_{n} \Rightarrow \mu$ as $n \rightarrow \infty$, converges weakly to a probability measure $\mu$. We write $Y_{n} \Rightarrow \mu$ (stably) as $n \rightarrow \infty$ if and only if $Y_{n} \Rightarrow \mu$ and for every $B \in \mathscr{A}$, with $P(B)>0$, there exists a measure $\mu_{B}$ such that $Y_{n} \Longrightarrow \mu_{B}(\cdot) / P(B)$ under the conditional measure $P(\cdot \mid B)$. In the special case when $\mu_{B}(\cdot)=\mu(\cdot) P(B)$ for all $B \in \mathscr{A}$ with $P(b)>0$ we write $Y_{n} \Rightarrow \mu$ (mixing). A survey of stable and mixing limit theorems, and the applications of these concepts, may be found in [5], [6], and [1].

Let $\mathscr{F} \subset \mathscr{A}$ be a $\sigma$-field. We write $Y_{n} \Rightarrow \mu$ (F stably) as $n \rightarrow \infty$, if and only if $Y_{n} \Rightarrow \mu$ and for every $B \in \mathscr{F}$ with $P(B)>0$ there exists a measure $\mu_{B}$ such that $Y_{n} \Longrightarrow \mu_{B}(\cdot) / P(B)$ as $n \rightarrow \infty$, under the conditional measure $P(\cdot \mid B)$.

In the special case when $\mu_{B}(\cdot)=\mu(\cdot) P(B)$ for all $B \in \mathscr{F}$ with $P(B)>0$ we write $Y_{n} \Rightarrow \mu$ (F mixing). Let us observe that if $Y_{n} \Rightarrow \mu$ (stably), then for every $\mathscr{F} \subset \mathscr{A} Y_{n} \Rightarrow \mu$ (F stably).

Let $\left\{B_{n}, n \geqslant 1\right\}$ be an increasing sequence of positive numbers such that

$$
\frac{B_{n}}{B_{n+1}} \rightarrow 1, \quad B_{n} \rightarrow \infty \quad \text { as } n \rightarrow \infty
$$


Let $\left\{Z_{n}, n \geqslant 1\right\}$ be a sequence of random variables such that, for every $n \geqslant 1$,

$$
P\left(Z_{n} \leqslant Z_{n+1}\right)=1 \text {. }
$$

Let $\left\{N_{n}, n \geqslant 1\right\}$ be a sequence of positive integer-valued random variables.

Here we present necessary and sufficient conditions under which $Z_{N_{n}} / B_{N_{n}} \Rightarrow \mu$, as $n \rightarrow \infty$, in the case where no assumption concerning the independence of the random variables $\left\{Z_{n}, n \geqslant 1\right\}$ and $\left\{N_{n}, n \geqslant 1\right\}$ is made. The presented theorems generalize the main results obtained in [2], [3], [4].

$\mathrm{D}$ a $\mathrm{f}$ i $\mathrm{n}$ i t i o $\mathrm{n}$. A sequence $\left\{N_{n}, n \geqslant 1\right\}$ of positive integer-valued random variables is said to satisfy, the condition $(\Delta)$ with norming sequence $\left\{B_{n}, n \geqslant 1\right\}$ if for every $\varepsilon>0$ and $\delta>0$ there exist a finite and measurable partition $A_{1}, A_{2}, \ldots, A_{M}$ of $\Omega$ and positive integers $a_{n j}, 1 \leqslant j \leqslant M, n \geqslant 1$, such that $a_{n j} \rightarrow \infty$ as $n \rightarrow \infty, 1 \leqslant j \leqslant M$, and

$$
\limsup _{n \rightarrow \infty} \sum_{j=1}^{M} P_{A_{j}}\left(\left|B_{N_{n}}-B_{a_{n} j}\right| \geqslant \delta B_{A_{n j}}\right) \leqslant \varepsilon,
$$

where $P_{A}(B)=P(A \cap B)$. and

Theorem 1. Let $\left\{Z_{n}, n \geqslant 1\right\}$ be a sequence of random variables such that (2) holds

$$
\frac{Z_{n}}{B_{n}} \Rightarrow \mu \quad \text { (stably) as } n \rightarrow \infty \text {. }
$$

Let $\left\{N_{n}, n \geqslant 1\right\}$ be a sequence of positive integer-valued random variables satisfying the condition $(\Delta)$ with norming sequence $\left\{B_{n}, n \geqslant 1\right\}$. If (1) holds, then

$$
\frac{Z_{N_{n}}}{B_{N_{n}}} \Rightarrow \mu \quad \text { (stably) as } n \rightarrow \infty \text {. }
$$

Assume (1) holds and

$$
\frac{B_{N_{n}}}{B_{n}} \stackrel{\mathbf{P}}{\longrightarrow} \lambda \quad \text { (in probability) as } n \rightarrow \infty,
$$

where $\lambda$ is a positive random variable.

Let $\mathscr{F}_{\lambda}$ denote the $\sigma$-field generated by the random variable $\lambda$.

Theorem 2. Let $\left\{Z_{n}, n \geqslant 1\right\}$ be a sequence of random variables. Let $\left\{N_{n}, n \geqslant 1\right\}$ be a sequence of positive integer-valued random variables. If (1), (2), and (3) hold, then the following conditions are equivalent:

$$
\begin{aligned}
& \frac{Z_{n}}{B_{n}} \Rightarrow \mu \quad\left(F_{\lambda} \text { stably }\right) \text { as } n \rightarrow \infty ; \\
& \frac{Z_{N_{n}}}{B_{N_{n}}} \Rightarrow \mu \quad\left(\mathscr{F}_{\lambda} \text { stably }\right) \text { as } n \rightarrow \infty .
\end{aligned}
$$

We also note that in Theorems 1 and 2 stable or $\mathscr{F}_{\lambda}$ stable convergence can be replaced by mixing or $\mathscr{F}_{\lambda}$ mixing convergence, respectively.

\section{REFERENCES}

1. Aldous D.J., Eagleson G.K. On mixing and stability of limit theorems. - Ann. Probab., 1978, v. 6, p. 325-331.

2. Gsörgö S. On limit distributions of sequences of random variables with random indices. - Acta Math. Acad. Sci. Hungar., 1974, v. 25, p. 227-232.

3. Kowalski $P$., Rychlik $Z$. Limit theorems for maximal random sums. - In: Asymptotic Methods in Probability and Statistics. Ed. by B. Szyszkowicz. Elsevier Science B. V., p. 13-29.

4. Круглов В.М., Чжая Бо. Предельные теоремы для максимальных случайных сумм. - Теория вероятн. и ее примен., 1969, т. 41, в. 3, с. 520-532. 
5. Rényi A. On mixing sequences of sets. - Acta Math. Acad. Sci., 1958, v. 9, p. 215228.

6. Rényi $A$. On stable sequences of events. - Sankhya A, 1963, v. 25, p. 293-302.

\section{Zempléni A. (Budapest, Hungary) Decompositions and anti-irreducibles in max-semigroups of bivariate random variables.}

1. Introduction. The famous theorem of Khinchin ensures that any distribution over the real line can be decomposed into the convolution product of irreducible distributions and a possible remainder term, a so-called anti-irreducible distribution. The anti-irreducibles in this structure turned out to be infinitely divisible distributions. We refer to these theorems as Theorem 1 (the decomposition theorem) and Theorem 2 (the infinite divisibility of anti-irreducibles), respectively.

Analogous theorems were proven by 'Ruzsa and Székely ([3]) for the elements of certain commutative semigroups. This theory of the so-called Hun and Hungarian semigroups was applicable to several interesting structures in probability theory (giving good reasoning why this subject is called «algebraic probability theory»).

We consider the semigroup $M(S)$ of all probability distribution functions on subsets $S$ of $\mathbf{R}^{2}$, where the operation is the pointwise multiplication of distribution functions (d.f.'s). $M(S)$ is a semigroup if $S$ is closed under the maximum operation. This structure corresponds to the coordinatewise maximum of $S$-valued independent random vectors. The above mentioned algebraic probability theory of Ruzsa and Székely is applicable to the case $S=\overline{\mathbf{R}_{+}^{2}}$. (The decisive condition is that the set of the max-divisors of every element in $S$ is compact. Thus the theorem in Zempléni [4] can be applied, ensuring the same properties for $M(S)$ ). Hence both Theorems 1 and 2 are true in $M\left(\overline{\mathbf{R}_{+}^{2}}\right)$ (the maximum-semigroup of bivariate distribution functions, corresponding to nonnegative random vectors). On the other hand, this is not the case for $M(S)$, in general.

2. Counterexamples. First we show that neither Theorem 1 nor Theorem 2 is true in $M(S)$ for $S=\mathbf{R}^{2}$ (or which is equivalent, in $M\left(\mathbf{R}_{+}^{2}\right)$ ).

The following theorem provides examples for nondecomposable d.f.'s in $M\left(\mathbf{R}_{+}^{2}\right)$ [5]. Its first part gives the decomposition of the given d.f. $F$ in $M\left(\overline{\mathbf{R}_{+}^{2}}\right)$. The nondecomposability of $F$ relies on the fact that the components $F_{i}(i=1,2)$ are concentrated to the boundary of $\mathbf{R}_{+}^{2}$, so they do not belong to $M\left(\mathbf{R}_{+}^{2}\right)$.

Theorem 3. Let $\operatorname{supp}(F)=T_{1} \cup T_{2}$, where $T_{1}=[0, a] \times\left[b_{1}, b_{2}\right]$ and $T_{2}=\left[a_{1}, a_{2}\right] \times$ $[0, b] ; 0<a<a_{1}<a_{2}, 0<b<b_{1}<b_{2}$. Let us denote $[0, a] \times[0, b]$ by $T_{1} \wedge T_{2}$ and suppose that $F$ is a continuous d.f., for which $\left.F\right|_{i}$ has independent components $(i=1,2)$. Then

1. The decomposition of $F$ into irreducibles in $M\left(\overline{\mathbf{R}_{+}^{2}}\right)$ has the form $F=\left(p \cdot F_{1}+\right.$ $\left.(1-p) \cdot F_{2}\right) \prod_{i=1}^{\infty} G_{j}$, where $\operatorname{supp}\left(F_{1}\right) \subset\left[a_{1}, a_{2}\right] \times\{0\}, \operatorname{supp}\left(F_{2}\right) \subset\{0\} \times\left[b_{1}, b_{2}\right]$ and $\operatorname{supp}\left(G_{j}\right) \subset T_{1} \wedge T_{2}$.

2. F has no decomposition of the form $F=\prod_{j=1}^{\omega} G_{j} \cdot H$, where $G_{j}$ is irreducible in $M(\mathbf{R})(j=1, \ldots)$ and $H$ is (max-)anti-irreducible.

E x a m p i e. An example for noninfinitely divisible anti-irreducible d.f. in $M\left(\mathbf{R}^{2}\right)$ is the following.

Let $\left(a_{n}\right)_{n=1}^{\infty}$ be a monotonic sequence of real numbers tending to $-\infty$ and $F_{n}$ be a max-irreducible d.f. on $T_{n}=\left[a_{n}, a_{n-1}\right] \times\left[a_{n}, a_{n-1}\right]$. To any probability distribution $\left(p_{n}\right)_{n=1}^{\infty}$, the d.f. $F=\sum_{n=1}^{\infty} p_{n} F_{n}$ is max-anti-irreducible, but it is obviously not max-infinitely divisible (see the characterization of max-infinitely divisible d.f.'s in [1]).

It can be shown that the other two possible combinations can also occur:

1. If we consider $M(S)$ for $S=\cup_{i=1}^{\infty} T_{n}$ (where the rectangles $T_{n}$ are defined in the example above), then for $M(S)$ the decomposition theorem remains valid, but the example above still implies that not all anti-irreducible distributions are infinitely divisible.

2. On the other hand, the following characterization for those $S \subset \mathbf{R}^{2}$, where $M(S)$ is a semigroup with a unit element (thus $S$ is bounded from below) such that Theorem 1 is true, can be proven [6]. 
Theorem 4. Let $x_{m}=\min S \in S$ and $S$ be a union of a finite number of convex sets. The Khinchin-type decomposition theorem does not hold in $M(S)$ if and only if there exists an $\underline{x}=\left(x_{1}, x_{2}\right) \in \bar{S} \backslash S$ and constants $\delta, \varepsilon>0$ such that either $\left(x_{1}-\delta-\varepsilon, x_{1}-\delta\right) \times\left(x_{2}, x_{2}+\right.$ $\varepsilon) \subset S$ and the interval $\left\{x_{1}\right\} \times\left(x_{2}, x_{2}+\varepsilon\right) \subset S$ or $\left(x_{1}, x_{1}+\varepsilon\right) \times\left(x_{2}-\varepsilon-\delta, x_{2}-\delta\right) \subset S$ and the interval $\left\{x_{1}, x_{1}+\varepsilon\right\} \times\left\{x_{2}\right\} \subset S$.

Corollary. Theorem 1 is not true for $M(S)$, where $S=[0,1] \times[0,1] \backslash(1,0)$.

It is easy to show that on the other hand Theorem 2 is valid for this structure $(M(S)$, where $S=[0,1] \times[0,1] \backslash(1,0))$.

$\mathrm{R}$ e $\mathrm{m}$ a $\mathrm{r}$ k. While the algebraic probability theory was developed for commutative semigroups only, some recent results for decompositions in noncommutative semigroups are given in $[2]$.

This work partially supported by the Hungarian FKFP Grant № 0429/1997 and by the Hungarian Scientific Research Grant № T-16665.

\section{REFERENCES}

1. Balkema A. A., Resnick S. I. Max-infinite divisibility. -- J. Appl. Probab., 1977, v. 14, p. 309-319.

2. Clark W.E, Holland W. Ch., Székely G. J. Decompositions in discrete semigroups. Studia Sci. Math. Hung., 1998, v. 34, № 1-3, p. 15-23.

3. Ruzsa I., Székely G.J. Algebraic Probability Theory. New York: Wiley, 1988.

4. Zempléni $A$. The heredity of Hun and Hungarian property. - J. Theor. Probab., 1990 , v. 3, p. 599-609.

5. Zempléni $A$. In the max-semigroup of probability measures over the plane there is no Khinchin-type decomposition theorem. - Studia Sci. Math. Hung., 1995, v. 30, p. 303-311.

6. Zempléni A. Max-semigroups of bivariate random variables with Khinchin-type decompositions. - Studia Sci. Math. Hung., to appear.

Zieliniski R. (Warsaw, Poland) High accuracy evaluation of cumulative distribution function of $\alpha$-stable symmetric distribution.

To calculate the distribution function $F_{\alpha}(x)$ of the symmetric $\alpha$-stable distribution with the characteristic function $\varphi(t)=\exp \left(-|t|^{\alpha}\right)$, the following formula is proposed

$$
F_{\alpha}(x)=\frac{1}{2}+\frac{1}{\pi} \int_{0}^{\infty} \frac{\sin y}{y} \exp \left\{-\left(\frac{y}{x}\right)^{\alpha}\right\} d y .
$$

The formula is based on a Gil-Pelaez result [2] (see also [3] and [1]) and to the best of my knowledge it has never been used in this form.

For numerical analysis formula (1) may be written in the form

$$
F_{\alpha}(x)=\frac{1}{2}+\frac{1}{\pi} \sum_{k=0}^{\infty} I_{k}(\alpha, x)
$$

where

$$
I_{k}(\alpha, x)=\int_{k \pi}^{(k+1) \pi} \frac{\sin y}{y} \exp \left\{-\left(\frac{y}{x}\right)^{\alpha}\right\} d y .
$$

Due to the fact that the alternating series in (2) is quickly converging and the integrands in (3) are smooth, one can easily control the numerical error of calculations. Applying the Richardson extrapolation scheme (a kind of the Romberg integration with the Gauss-Legendre instead of the standard trapezoid rule) to calculation of integrals (3) and the Euler transformation scheme for summing up the series in (2), gave us in a standard Turbo-Pascal implementation the accuracy of 10 decimals. 


\section{REFERENCES}

1. Csörgö S. Gil-Pelaez-Rosén transformation of data. - Austr. J. Statist., 1983, v. 25, p. $437-441$.

2. Gil-Pelaez J. Note on the inversion theorem. - Biometrika, 1951, v. 38, p. 481-482.

3. Wendel J. G. The non-absolute convergence of Gil-Pelaez' inversion integral. - Ann. Math. Statist., 1961, v. 32, p. 338-339.

Кашеев Д. Е. (Тверь, Россия) Цена опциона для случая логустойчивого распределения базового актива.

Рассматривается задача расчета стоимости опциона купли Европейского типа на акции. Предполагается, что по базовому активу (акциям) в течение действия контракта не выплачиваются дивиденды.

1. Рассмотрим $(B, S)$-рынок ценных бумаг, состоящий из двух активов: «безрисковой» облигации $B$ и «рисковой》 акции $S$.

Стоимость облигации $B=\left(B_{t}\right)_{t \geqslant 0}$ эволюционирует по закону

$$
B(t)=B(0) \exp \{r t\}, \quad B(0)>0,
$$

где $r>0-$ безрисковая процентная ставка.

Динамика стоимости акции $S=\left(S_{t}\right)_{t \geqslant 0}$ удовлетворяет соотношению

$$
S(t)=S(0) \exp \{X(t)\}, \quad S(0)>0,
$$

где $X(t)$ - процесс со стационарными и независимыми прирацениями.

Мы полагаем, что $X(1)$ имеет симметричное устойчивое распределение с характеристическим показателем $\alpha<2$.

По определению рассматриваемый $(B, S)$-рынок является рынком «без трения». Предположим, что на данном рынке заключен опционный контракт купли Европейского тила на акции с моментом исполнения $T$ и функцией платежа $F(T)=$ $\max \{0, S(T)-K\}$.

2. Обозначим $\eta=X(T)$. Разобьем интервал времени $[0, T]$ на $n$ равных подынтервалов:

$$
\eta=\eta_{n 1}+\cdots+\eta_{n n}
$$

где $\eta_{n i}=X(i \Delta t)-X((i-1) \Delta t)$ и $\eta_{n i}-$ независимые одинаково распределенные случайные величины.

Вместо $\eta_{n i}$ рассмотрим случайные величины

$$
\xi_{n i}=\eta_{n i} I\left\{\left|\eta_{n i}\right| \leqslant C_{n}\right\}+C_{n} I\left\{\eta_{n i}>C_{n}\right\}-C_{n} I\left\{\eta_{n i}<-C_{n}\right\} .
$$

Уровень урезания $C_{n}$ выбирается из условия

$$
\sum_{n=1}^{\infty} P\left(A_{n}\right)<\infty
$$

тде $A_{n}=\bigcup_{i=1}^{n}\left\{\left|\eta_{n i}\right|>C_{n}\right\}$

Поскольку $P\left(A_{n}\right) \sim 2 C_{n}^{-\alpha} A$ для $\alpha<2$, то для сходимости ряда (5) достаточно потребовать сходимость ряда $\sum_{n=1}^{\infty} C_{n}^{-\alpha}$. В частности, можно выбрать $C_{n}=$ $n^{1 / \alpha}(\ln n)^{(1+\varepsilon) / \alpha}$.

Образуем $L_{n}=\xi_{n 1}+\cdots+\xi_{n n}$ и

$$
S_{n}(T)=S(0) \exp \left\{L_{n}\right\} .
$$

На настоящий момент не существует общепризнанного определения рациональной стоимости для случая, когда логарифмы стоимостей базовых активов устойчивы $(\alpha<2)$. Автор предлагает рациональной стоимостью опционного контракта $C^{*}$ в 
рассматриваемой модели (1), (2) называть $C^{*}=\lim _{n \rightarrow \infty} C_{n}^{*}$, где $C_{n}^{*}$ есть рациональная стоимость соответству ющего контракта в модели, и стоимость базового актива удовлетворяет (6).

3. Отыщем рациональную стоимость опциона $C_{n}^{*}$ с базовым активом (6), руководствуясь теорией арбитража.

Поскольку урезанные величины $\xi_{n i}$ обладают экспоненциальными моментами, то в качестве риск-нейтральной меры, по которой будут проводиться расчеты, выберем меру Эсшера.

Параметр $n$-й риск-нейтральной меры Эсшера $h_{n}$ определяется из уравнения

$$
\exp \left\{\frac{r T}{n}\right\}=\frac{\mathbf{E} \exp \left\{\left(1+h_{n}\right) \xi_{n 1}\right\}}{\mathbf{E} \exp \left\{h_{n} \xi_{n 1}\right\}}
$$

Начиная с некоторого номера $n$, единственное решение уравнения (7) $h_{n} \in$ $\left(-\frac{1}{2},-\frac{1}{2}+1 / n^{1 / \alpha}\right)$.

Следуя [1], [2],

$$
C_{n}^{*}=S(0) P_{h_{n}+1}\left\{S_{n}(T)>K\right\}-K \exp \{-r T\} \mathbf{P}_{h_{n}}\left\{S_{n}(T)>K\right\}
$$

где

$$
\mathbf{P}_{h_{n}}\left\{S_{n}(T)>K\right\}:=\left[\mathbf{E} e^{h_{n} \xi_{n 1}}\right]^{-n} \int_{\ln K / S(0)}^{\infty} \exp \left\{h_{n} x\right\} d F_{L_{n}}(x)
$$

Tak Kak

$$
\mathbf{P}_{h_{n}+1}\left\{S_{n}(T)>K\right\}>\left[\frac{\int_{\ln K / S(0)}^{\infty} \exp \left\{\left(1+h_{n}\right) x\right\} d F_{\xi_{n 1}}(x)}{\mathbf{E} e^{\left(1+h_{n}\right) \xi_{n 1}}}\right]^{n} \sim 1,
$$

то $\mathbf{P}_{h_{n}+1}\left\{S_{n}(T)>K\right\} \rightarrow 1, n \rightarrow \infty$. Аналогично, $\mathbf{P}_{h_{n}}\left\{S_{n}(T)>K\right\} \rightarrow 0, n \rightarrow \infty$.

Отсюда $C^{*} \rightarrow S(0)+0, n \rightarrow \infty$.

Можно показать, что $S(0)$ является верхней ценой и, более того, она не достигается ни при какой стратегии.

\section{СПИСОК ЛИТЕРАТУРЫ}

1. Gerber H.U., Shiu E.S.W. Martingale approach to pricing American options. ASTIN Bulletin, 1994, v. 24, p. 195-200.

2. Gerber H. U., Shiu E.S.W. Option pricing by Esscher transforms. - Transactions of the Society of Actuaries, 1994, v. 46, p. 99-191.

Королев В. Ю. (Москва, Россия), Учайкин В.В. (Ульяновск, Россия) Некоторые предельные теоремы для обобшенных процессов восстановления с тяжелыми хвостами.

Пусть $X_{1}, X_{2}, \ldots$ - независимые одинаково распределенные (о.p.) случайные величины (с.в.). Предположим, что их общее распределение принадлежит к области притяжения строго устойчивого распределения $G_{\alpha, \theta}(x)$, определяемого своей характеристической функцией

$$
g_{\alpha, \theta}(s)=\exp \left\{-|s|^{\alpha} \exp \left(-i \frac{\pi \alpha \theta}{2} \operatorname{sign} s\right)\right\}, \quad s \in \mathbf{R},
$$

где $0<\alpha \leqslant 2,|\theta| \leqslant \theta_{\alpha}=\min \{1,2 / \alpha-1\}$. Этот факт будет записываться в виде $\mathscr{L}\left(X_{1}\right) \in D A\left(G_{\alpha, \theta}\right)$.

Пусть, далее, $T_{1}, T_{2}, \ldots$ - о.p. неотрицательные с.в., независимые как между собой, так и от последовательности $X_{1}, X_{2}, \ldots$ Предположим, что $\mathscr{L}\left(T_{1}\right) \in D A\left(G_{\beta, 1}\right)$ c $\beta \leqslant 1$. 
Пусть $N(t), t>0,-$ процесс восстановления, определяемый соотношением

$$
\sum_{n=1}^{N(t)} T_{n} \leqslant t<\sum_{n=1}^{N(t)+1} T_{n}, \quad t>0 .
$$

Рассмотрим обобщенный процесс восстановления $S(t)=\sum_{n=1}^{N(t)} X_{n}, t>0$ (для определенности мы полагаем $\sum_{n=1}^{0}=0$ ). Наша цель - изучить асимптотическое поведение $S(t)$ при $t \rightarrow \infty$. Символ $\Longrightarrow$ будет обозначать слабую сходимость. Стандартная нормальная функция распределения, как всегда, будет обозначаться $\Phi(x)$.

Теорема 1. B сделанных выше предположениях о с.в. $\left\{T_{i}\right\}_{i \geqslant 1}$ u $\left\{X_{i}\right\}_{i \geqslant 1}$ кайдется конечная положительная постовнная $c=c(\alpha, \beta, \theta)$ тахая, ито

$$
\mathbf{P}\left\{\frac{S(t)}{c t^{\beta / \alpha}}<x\right\} \Longrightarrow \int_{0}^{\infty} G_{\alpha, \theta}\left(x u^{\beta / \alpha}\right) d G_{\beta, 1}(u), \quad t \rightarrow \infty .
$$

Доказательство этого результата может быть получено в качестве следствия «теоремы переноса» для суперпозиций независимых случайных процессов, доказанной в [1] (см. также [2, гл. А2.2]).

3 а м е ч а н и е 1. Используя так называемую теорему умножения (см., например, теорему 3.3.1 в [3]), можно убедиться, что в случае $\theta=0$ предельное распределение в теореме 1 представляет собой масштабную смесь нормальных законов $\int_{0}^{\infty} G_{\alpha, 0}\left(x u^{\beta / \alpha}\right) d G_{\beta, 1}(u)=\int_{0}^{\infty} \Phi(x u) d F(u)$ со смешивающим распределением

$$
F(u)=\int_{0}^{\infty} G_{\beta, 1}\left((u \sqrt{z})^{\alpha / \beta}\right) d G_{\alpha / 2,1}(z)=\int_{0}^{\infty}\left[1-G_{\alpha / 2,1}\left(\left(z^{\beta / \alpha} / u\right)^{2}\right)\right] d G_{\beta, 1}(z),
$$

$u \geqslant 0$ и $F(u)=0$ для $u<0$.

Теорема 1 дает приближенное (для больших $t$ ) распределение координаты частицы при случайном блуждании с задержками: на $i$-м шаге частица мгновенно перемешается в новую точку на расстоянии $\left|X_{i}\right|$ от предыдущей и пребывает там некоторое время $T_{i}$ до следуюшего перемещения. Несложно видеть, что рассматриваемая схема в некотором смысле симметрична и может быть легко преобразована для изучения асимптотики времени первого прохождения частицы через удаленную границу. А именно, в дополнение к сделанным выше предположениям, мы ужесточим требования к с.в. $X_{1}, X_{2}, \ldots$ предположим, что эти с.в. неотрищательны и $\mathscr{L}\left(X_{1}\right) \in D A\left(G_{\alpha, 1}\right)$ c $\alpha \leqslant 1$.

Пусть $M(x), x \geqslant 0,-$ процесс восстановления, определяемый условием

$$
\sum_{i=1}^{M(x)} X_{i} \leqslant x<\sum_{i=1}^{M(x)+1} X_{i}, \quad x \geqslant 0 .
$$

Тогда с.в. $T(x)=\sum_{n=1}^{M(x)} T_{n}$ может быть интерпретирована как «время первого прохождения》 через гранищу $x$ лри случайном блуждании с задержками. Точно так же, как теорему 1, можно доказать следуюшее утверждение.

Теорема 2. В сделаняых выше предположениях о с.в. $\left\{T_{i}\right\}_{i \geqslant 1} u\left\{X_{i}\right\}_{i \geqslant 1}$ суиестөует конечная положительная константа $c_{0}=c_{0}(\alpha, \beta)$ такая, что

$$
\mathbf{P}\left\{\frac{T(x)}{c_{0} x^{\alpha / \beta}}<t\right\} \Longrightarrow \int_{0}^{\infty} G_{\beta, 1}\left(t u^{\alpha / \beta}\right) d G_{\alpha, 1}(u), \quad x \rightarrow \infty .
$$

В контексте случайного блуждания с задержками распределения

$$
P(x)=\int_{0}^{\infty} G_{\alpha, 1}\left(x u^{\beta / \alpha}\right) d G_{\beta, 1}(u) \quad \text { и } \quad Q(t)=\int_{0}^{\infty} G_{\beta, 1}\left(t u^{\alpha / \beta}\right) d G_{\alpha, 1}(u)
$$

резонно называть сопряженными относительно пространства и времени. 
В сообщении также обсуждаются аналитические свойства предельных распределений в теоремах 1 и 2, равно как и примеры физических задач, приводящих к подобным моделям.

Работа выполнена при поддержке РФФИ, проекты 97-01-00273, 98-01-03307, 99-01-00846 и 99-01-00847.

\section{СПИСОК ЛИТЕРАТУРЫ}

1. Korolev V. Yu. A general theorem on the limit behavior of superpositions of independent random processes with applications to Cox processes. - J. Math. Sci., 1996, v. 81 , № 5 , p. 2951-2956.

2. Gnedenko B. V., Korolev V. Yu. Random Summation: Limit Theorems and Applications. Boca Raton: CRC Press, Fl, 1996.

3. Золотарев B. M. Одномерные устойчивые распределения. М.: Наука, 1983.

4. Uchaikin V. V., Zolotarev V.M. Chance and Stability. Stable Distributions and their Applications. Utrecht: VSP, 1999.

Maejima M. (Yokohama, Japan), Sato K.-I. (Nagoya, Japan), Watanabe T. (Aizu, Japan) Operator semi-selfdecomposable distributions and operator semistable distributions.

Let $0<b<1, Q$ be a $(d \times d)$-matrix whose eigenvalues have positive real parts, $I\left(\mathbf{R}^{d}\right)$ be the class of all infinitely divisible distributions on $\mathbf{R}^{d}$, and let $m$ be a nonnegative integer. Set $L_{-1}(b, Q)=I\left(\mathbf{R}^{d}\right)$. A probability distribution $\mu \in I\left(\mathbf{R}^{d}\right)$ is said to belong to the class $L_{m}(b, Q)$ if there exists $\rho \in L_{m-1}(b, Q)$ such that $\widehat{\mu}(z)=\widehat{\mu}\left(b^{Q^{\prime}} z\right) \widehat{\rho}(z)$, where « means the characteristic function of distribution, $Q^{\prime}$ is the transpose of $Q$, and $b^{Q^{\prime}}=$ $\sum_{n=0}^{\infty}(n !)^{-1}(\log b)^{n}\left(Q^{\prime}\right)^{n}$. This definition is equivalent to the following: A probability distribution belongs to the class $L_{m}(b, Q)$ if there exist independent $\mathbf{R}^{d}$-valued random variables $\left\{X_{j}\right\}, a_{n}>0, a_{n} \uparrow \infty, c_{n} \in \mathbf{R}^{d}, k_{n} \in \mathbf{N}, k_{n} \uparrow \infty$, such that

$$
\begin{gathered}
\lim _{n \rightarrow \infty} \frac{a_{n}}{a_{n+1}}=b, \quad \mathscr{L}\left(X_{j}\right) \in L_{m-1}(b, Q), \quad \mathscr{L}\left(a_{n}^{-Q} \sum_{j=1}^{k_{n}} X_{j}+c_{n}\right) \rightarrow \mu, \\
\lim _{n \rightarrow \infty} \max _{1 \leqslant j \leqslant k_{n}} \mathbf{P}\left\{\left|a_{n}^{-Q} X_{j}\right|>\varepsilon\right\}=0 \quad \forall \varepsilon>0,
\end{gathered}
$$

where $\mathscr{L}(X)$ is the law of a random variable $X$. Define also $L_{\infty}(b, Q)$ by $\bigcap_{m \geqslant 0} L_{m}(b, Q)$. Furthermore, let $\operatorname{OSS}(b, Q)$ be the class of $\mu \in I\left(\mathbf{R}^{d}\right)$ such that $\widehat{\mu}(z)^{a}=\widehat{\mu}\left(b^{Q^{\prime}} z\right) e^{i\langle c, z\rangle}$ for some $0<a<1$ and $c \in \mathbf{R}^{d}$. Then we have

$$
I\left(\mathbf{R}^{d}\right) \supset L_{0}(b, Q) \supset \cdots \supset L_{m}(b, Q) \supset \cdots \supset L_{\infty}(b, Q) \supset \operatorname{OS} S(b, Q),
$$

and we say that $\mu \in L_{0}(b, Q)$ is operator semi-selfdecomposable, $\mu \in L_{\infty}(b, Q)$ is completely operator semi-selfdecomposable, and $\mu \in O S S(b, Q)$ is operator semi-stable.

A class $H \subset I\left(\mathbf{R}^{d}\right)$ is said to be $Q$-completely closed in the strong sense if $H$ is closed under weak convergence, convolution and $Q$-type equivalence, and is closed under going to the $t$ th convolution power for any $t>0$. Here $H$ is said to be closed under $Q$-type equivalence if $\mathscr{L}(X) \in H, a>0$ and $c \in \mathbf{R}^{d}$ imply $\mathscr{L}\left(a^{-Q} X+c\right) \in H$. We can easily see from the definition that $L_{m}(b, Q), 0 \leqslant m \leqslant \infty$, are $Q$-completely closed in the strong sense, since $L_{-1}(b, Q)=I\left(\mathbf{R}^{d}\right)$ is so.

Our main theorem is the following.

Theorem. The class $L_{\infty}(b, Q)$ is the smallest $Q$-completely closed class in the strong sense containing the class $O S S(b, Q)$.

To show the theorem, we need to characterize the Lévy measure and the Gaussian part of $\mu \in L_{\infty}(b, Q)$, respectively. One of byproducts is the following: Let $s$ be a number of distinct absolute values of eigenvalues of $b^{Q}$. If $\mu$ is a mean zero Gaussian distribution in $L_{\infty}(b, Q)$, then $\mu$ can be expressed as the convolution of at most $s$ mean zero Gaussian distributions in $O S S(b, Q)$. 
Matysiak W., Szabłowski P. J. (Warsaw, Poland) On some inequalities satisfled by characteristic functions.

1. Introduction. The problem of specifying whether a given function is characteristic or not is an important and difficult question. Many of the useful criteria have the form of inequalities. Let $X$ be a real random variable with distribution $\mu$ and characteristic function $f$. Set $\alpha_{j}=\int x^{j} d \mu(x)$ (if it exists). Ushakov [4] proved that if $\alpha_{1}=0$ and $\alpha_{2}<\infty$, then $\operatorname{Re} f(t) \geqslant 1-\alpha_{2} t^{2} / 2$ for all $t \in \mathbf{R}$. Rossberg [3] (see also recent book [2]) sharpened the result of Ushakov.

Theorem 1. If $f$ is a real characteristic function then $f(t) \geqslant \cos \sqrt{\alpha_{2}}$ for all $\alpha_{2}|t| \leqslant$ $\pi$. Equality holds for some $t \neq 0$ if and only if $\mu$ is symmetric with a support consisting of two elements.

Dreier [1] (also [2]) using the above inequality obtained the following estimate:

Theorem 2. If $\mu \neq \delta_{0} f$ is real and $\alpha_{4}<\infty$, then

$$
f(t) \leqslant 1-\frac{\alpha_{2}^{2}}{\alpha_{4}}+\frac{\alpha_{2}^{2}}{\alpha_{4}} \cos \sqrt{\frac{\alpha_{4}}{\alpha_{2}}} t \text { for all } \sqrt{\frac{\alpha_{4}}{\alpha_{2}}}|t| \leqslant \pi .
$$

Equality holds for some $t \neq 0$ if and only if $\mu$ is symmetric with a support consisting of two or three elements.

In this paper we present a unified approach to obtain the above theorems. Our method sheds some new light on the nature of these inequalities. Moreover, our framework allows to get arbitiarily large number of next, sharper inequalities, greatly improving the results of Rossberg and Dreier.

2. Inequalities - general scheme. Define

$$
m_{n}^{X}(t):=\min _{a_{j} \in \mathscr{C}} \mathbf{E}\left|\exp (i t X)-\sum_{j=0}^{n} a_{j} X^{j}\right|^{2}, \quad n \in \mathbf{N} \bigcup\{0\}, \quad t \in \mathbf{R} .
$$

(Of course, whenever we write $m_{n}^{X}$ or consider the inequality associated with it, we assume that at least a moment of order $2 n$ exists.) Obviously, for all $n \in \mathbf{N}, t \in \mathbf{R}$ we have $m_{n}^{X}(t) \geqslant 0$ and $m_{n+1}^{X}(t) \leqslant m_{n}^{X}(t)$.

There is no theoretical difficulty in calculating $m_{n}^{X}$ - it is just a linear regression: $m_{n}^{X}(t)=\operatorname{Var}(\exp (i t X))-\Lambda_{n}(t) \Sigma_{n}^{-1} \Lambda_{n}^{*}(t)=1-|f(t)|^{2}-\Lambda_{n}(t) \Sigma_{n}^{-1} \Lambda_{n}^{*}(t)$, where $\Lambda_{n}(t)=\left[\operatorname{Cov}\left(\exp (i t X), X^{j}\right)\right]_{j=1}^{n}$ and $\Sigma_{n}=\left[\operatorname{Cov}\left(X^{j}, X^{k}\right)\right]_{j, k=1}^{n}$. (Here symbol $\ll^{T} \gg$ stands for transposition and « $^{*}$ for Hermitian (conjugate) transposition.) Writing the above expression we assume that $\Sigma_{n}$ is reversible. We can now rewrite the inequalities $m_{n}^{X}(t) \geqslant 0(n \in \mathbf{N}, t \in \mathbf{R})$ as the following differential inequalities.

Theorem 3. For all $n \in \mathbf{N}$ and $t \in \mathbf{R}$, we have $1-|f(t)|^{2}-\Lambda_{n}(t) \Sigma_{n}^{-1} \Lambda_{n}^{*}(t) \geqslant 0$.

Characteristic functions which are solutions of the equations $m_{n}^{X}(t) \equiv 0$ seem to play crucial role in solving the inequalities from Theorem 3.

Theorem 4. The equation $m_{n}^{X}(t) \equiv 0$ is satisfied iff the support of $X$ consists of at most $n+1$ elements.

2.1. Inequalities - special cases. If $f$ is a real function, then applying Theorem 3 for $n \leqslant 3$ we obtain inequalities

$$
\begin{aligned}
& m_{0}^{X}(t)=1-f^{2}(t) \geqslant 0, \\
& m_{1}^{X}(t)=m_{0}^{X}(t)-\frac{\left[f^{\prime}(t)\right]^{2}}{\alpha_{2}} \geqslant 0, \\
& m_{2}^{X}(t)=m_{1}^{X}(t)-\frac{\left[\alpha_{2} f(t)+f^{\prime \prime}(t)\right]^{2}}{\alpha_{4}-\alpha_{2}^{2}} \geqslant 0, \\
& m_{3}^{X}(t)=m_{2}^{X}(t)-\frac{\left[\alpha_{4} f^{\prime}(t)+\alpha_{2} f^{(3)}(t)\right]^{2}}{\alpha_{2}\left(\alpha_{6} \alpha_{2}-\alpha_{4}^{2}\right)} \geqslant 0 .
\end{aligned}
$$


The first inequality gives a general necessary condition for characteristic functions. Solving differential inequalities (3) and (4) one gets the results of Theorems 1 and 2, respectively. Numerous examples allow to make the following conjecture about the solution of (5).

Conjecture. If $f$ is a real characteristic function and $\alpha_{6}<\infty$, then there exists a constant $c=c\left(\alpha_{2}, \alpha_{4}, \alpha_{6}\right)$ such that for all $|t| \leqslant c$.

$$
\begin{aligned}
f(t) \geqslant & \frac{\sqrt{r^{2}-4 s}+\left(r-2 \alpha_{2}\right)}{2 \sqrt{r^{2}-4 s}} \cos \left(t \sqrt{\frac{r-\sqrt{r^{2}-4 s}}{2}}\right) \\
& +\frac{\sqrt{r^{2}-4 s}-\left(r-2 \alpha_{2}\right)}{2 \sqrt{r^{2}-4 s}} \cos \left(\sqrt{\frac{r+\sqrt{r^{2}-4 s}}{2}}\right)
\end{aligned}
$$

where $r=\left(\alpha_{6}-\alpha_{2} \alpha_{4}\right) /\left(\alpha_{4}-\alpha_{2}^{2}\right), s=\left(\alpha_{2} \alpha_{6}-\alpha_{4}^{2}\right) /\left(\alpha_{4}-\alpha_{2}^{2}\right)$.

Acknowledgment. The authors thank H.-J. Rossberg for helpful discussions and bibliographical information.

\section{REFERENCES}

1. Dreier I. Ungleichungen Für Reelle Charakteristische Funktionen und Zugehörige Momente. - Ph. D. thesis, Technische Universität Dresden, 1999.

2. Laue G., Riedel M., Rossberg H.-J. Unimodale und positiv definite Dichten. Stuttgart: B. G. Teubner, 1999.

3. Rossberg H.-J. Positiv definite Verteilungsdichten. In: Gnedenko B.W. Einführung in Die Wahrscheinlichkeitstheorie, Berlin: Akademie-Verlag, 9th ed., 1991.

4. Ushakov N. G. Lower and upper bounds for characteristic functions. - J. Math. Sci., 1997 , v. 84 , № 3, p. 1179-1189.

Misiewicz J. (Zielona Góra, Poland) Symmetric stable random vector is isotropic only if it is sub-Gaussian.

A random vector $\left(X_{1}, \ldots, X_{n}\right)$ is called $\ell_{p}$ isotropic if, roughly, it has a density, except for a possible atom at zero, and if this density is constant on the $\ell_{p}$-spheres of $\mathbf{R}^{n}$. We want to extend this definition to the random vectors which distribution is not absolutely continuous with respect to the Lebesgue measure and to «spheres» which are not $\ell_{p}$ spheres on $\mathbf{R}^{n}$.

Let $q: \mathbf{R}^{n} \mapsto[0, \infty)$ be a quasi-norm on $\mathbf{R}^{n}$, i.e., the function $q$ is continuous and such that $q(t x)=|t| q(x)$ for every $t \in \mathbf{R}$ and every $x \in \mathbf{R}^{n}$. The triangular inequality is not required but, for the convenience, 'we will assume that $q(x)=0$ if and only if $x=0$, to avoid the situation that the considered distribution on $\mathbf{R}^{n}$ is in fact concentrated on less dimensional space.

We define the random vector $U$ on the «unit sphere» $S=\left\{x \in \mathbf{R}^{n}: q(x)=1\right\}$ having the distribution concentrated on $S$ and defined by the differential form

$$
\omega(d x)=c(n, q) \sum_{j=1}^{\infty}(-1)^{j+1} x_{j} d x_{1} \cdots d x_{j-1} d x_{j+1} \cdots d x_{n},
$$

where $c(n, q)$ is the normalizing constant.

$\mathrm{D}$ e $\mathrm{f}$ i $\mathrm{n}$ i t $\mathrm{i}$ o $\mathrm{n}$. A random vector $X=\left(X_{1}, \ldots, X_{n}\right)$ is isotropic if there exists a quasi-norm $r$ on $\mathbf{R}^{n}$ and a nonnegative random variable $\Theta$ independent of $U$ on $S$ such that $X \stackrel{\mathrm{d}}{=} U \cdot \Theta$.

Notice that this definition coincides with the natural definition of $\ell_{p}$-isotropic random is given by the $\ell_{p}$-norm $\|\cdot\|_{p}$ on $\mathbf{R}^{n}$. Indeed, if $X$ is $\ell_{p}$-isotropic, then 
its density is of the form $f(\|x\|)$ for some measurable and integrable function $f$ on $\mathbf{R}$. Writing now the vector $X$ in the form

$$
X=\left(\frac{X_{1}}{\|X\|_{p}}, \ldots, \frac{X_{n}}{\|X\|_{p}}\right)\|X\|_{p},
$$

we can easily see that $U=X /\|X\|_{p}$ and $\Theta=\|X\|_{p}$ are independent and the density of the variable $\Theta$ is equal to $c\left(n,\|\cdot\|_{p}\right)^{-1} f(r)$.

In the paper we study main properties of isotropic vectors on $\mathbf{R}^{n}$. For the purpose of the following result, connecting isotropic and stable vectors it is enough to consider $n=2$.

Lemma. Assume that a symmetric random vector $(R, S)$ has compact support in $\mathbf{R}^{2}$, and assume that a symmetric $\alpha$-stable random vector $X=\left(X_{1}, X_{2}\right)$ has the same distribution as $(R, S) \Theta$ for some nonnegative random variable $\Theta$ independent of $(R, S)$. Then $X$ is sub-Gaussian.

$\mathrm{P}$ r o $\circ \mathrm{f}$. Let $R_{1}$ be a random variable with the same distribution as $R$ independent of $R, S$, and $\Theta$. We will consider the random vector $Y=X\left|R_{1}\right|$. Since $X$ is symmetric $\alpha$-stable, the characteristic function of $Y$ can be written in the following way:

$$
\varphi(a, b)=\mathbf{E} \exp \left\{i\left(a X_{1}+b X_{2}\right)\left|R_{1}\right|\right\}=\mathbf{E} \exp \left\{-c(a, b)^{\alpha}|R|^{\alpha}\right\}
$$

where the quasi-norm $c$ is defined as the $L_{\alpha}$ norm appearing in the characteristic function of $X: \mathbf{E} \exp \left\{i\left(a X_{1}+b X_{2}\right)\right\}=\exp \left\{-c(a, b)^{\alpha}\right\}$. On the other hand, we have

$$
\varphi(a, b)=\mathbf{E} \exp \{i(a R+b S) Q\}
$$

where $Q=\Theta\left|R_{1}\right|$. Both formulas coincide for all $a, b \in \mathbf{R}^{2}$. For $b=0$ we obtain

$$
\mathbf{E} \exp \left\{i a X_{1}|R|\right\}=\frac{1}{2} \mathbf{E} \exp \{i a|R| Q\}+\frac{1}{2} \mathbf{E} \exp \{-i a|R| Q\}
$$

which means that the random variable $\widetilde{Q}$ defined as $\widetilde{Q}=Q$ with probability $\frac{1}{2}$ and $\widetilde{Q}=-Q$ with probability $\frac{1}{2}$ has the same distribution as $X_{1}$, i.e., symmetric $\alpha$-stable with the characteristic function $\exp \left\{-|a|^{\alpha} c(1,0)^{\alpha}\right\}$. Since the random vector $(R, S)$ is symmetric it is easy to see that $(R, S) Q$ has the same distribution as $(R, S) \widetilde{Q}$. Finally we obtain that for every fixed $k \in \mathbf{R}$

$$
\mathbf{E} \exp \left\{-c(a, k a)^{\alpha}|R|^{\alpha}\right\}=\mathbf{E} \exp \{i(a R+k a S) \tilde{Q}\}=\mathbf{E} \exp \left\{-|a R+k a S|^{\alpha}\right\} .
$$

The above equality we treat as the equality of Laplace transforms of two nonnegative random variables at the point $|a|^{\alpha}$ which implies that for every $k \in \mathbf{R}$ the random variables $c(1, k)^{\alpha}|R|^{\alpha}$ and $|R+k s|^{\alpha}$ have the same distribution. Since the random vector $(R, S)$ has compact support, then every its weak moment is finite and we have

$$
c(a, b)^{2} \mathbf{E} R^{2}=a^{2} \mathbf{E}\left(c(1, k)^{\alpha}|R|^{\alpha}\right)^{2 / \alpha}=a^{2} \mathbf{E}\left(|R+k S|^{\alpha}\right)^{2 / \alpha}=\mathbf{E}|a R+b S|^{2} .
$$

This shows that the function $c(a, b)$ is $L_{2}$-norm on $\mathbf{R}^{2}$. Now it is easy to see that $X$ has the same distribution as $\Gamma \Theta_{\alpha / 2}$, where $\Theta_{\alpha / 2}$ is $\alpha / 2$-stable positive random variable with the Laplace transform $\exp \left\{-2 t^{\alpha / 2}\right\}$ independent of the symmetric Gaussian random vector $\Gamma$ with the covariance matrix $\left(\mathbf{E}\left(R^{i} S^{j}\right)\right)_{i+j=2}$, which ends the proof.

As an easy consequence of the lemma we have the following:

Theorem. Assume that a symmetric $\alpha$-stable random vector $X=\left(X_{1}, X_{2}\right)$ is isotropic with the quasi-norm q: $\mathbf{R}^{2} \mapsto[0, \infty)$. Then $X$ is sub-Gaussian and the quasinorm $q$ is a norm defined by an inner product in $\mathbf{R}^{2}$. 


\section{REFERENCES}

1. Feller W. An introduction to probability theory and its application. New York: Wiley, 1996.

2. Gupta R.D., Misiewicz J.K., Richards D.St.P. Infinite sequences with signsymmetric Liouville type distributions. - Probab. Math. Statist., 1996, v. 16, № 1, p. $29-44$.

3. Richards D.St.P. Positive definite symmetric functions on finite dimensional spaces. - Statist. Probab. Lett., 1985, v. 3, p. 325-329.

4. Richards D.St.P. Positive definite symmetric functions on finite dimensional spaces. I. Application of the Radon transform. - J. Multivariate Anal., 1986, v. 19, p. $280-298$.

Móri T. F. (Budapest, Hungary) Heads vs tails.

1. Introduction. Consider an infinite sequence of tosses with a symmetric coin. The mathematical model is an independent identically distributed sequence of Bernoulli random variables $X_{1}, X_{2}, \ldots, \mathbf{P}\{$ head $\}=\mathbf{P}\{$ tail $\}=\frac{1}{2}$. For every positive integer $n$ let $Z_{H}(n)$ and $Z_{T}(n)$ denote the lengths of the longest pure head run and tail run, respectively, observed during the first $n$ tosses.

Distributional properties of these quantities have been known for a long time. The asymptotic formula $\mathbf{P}\left\{Z_{H}(n)<k\right\}=\exp \left(-n 2^{-k-1}\right)+o(1)$ has been re-discovered several times, and it can be traced back even to the 40's [3] (in fact, the remainder is $O\left(n^{-1} \log n\right.$ ) uniformly in $k$ ). The a.s. asymptotic behavior of $Z_{H}(n)$ was first investigated in [2].

It is easy to see that $Z_{H}(n)$ and $Z_{T}(n)$ are asymptotically independent. Let lg denote logarithm to the base $2, N=[\lg n], \alpha=1-\{\lg n\}$, where $[\cdot]$ and $\{\cdot\}$ stand for integer and fractional part, respectively, and introduce

$$
F(x)=\exp \left(-2^{-x-1}\right), \quad \varrho_{k}(x)=F(k+x)-F(k+x-1), \quad k \in \mathbf{Z} .
$$

This $F$ is a Gumbel type extreme value distribution and $\varrho$ is a discretized version of $F$, depending also on the real parameter $x$. Then ([4])

$$
\sum_{k=-\infty}^{\infty}\left|\mathbf{P}\left\{Z_{H}(n)-N=k, Z_{T}(n)-N=\ell\right\}-\varrho_{k}(\alpha) \varrho_{\ell}(\alpha)\right|=O\left(\frac{\log ^{3} n}{n}\right) .
$$

Hence no limit distribution exists: there is a periodicity by $\lg n$ in the asymptotic distribution.

2. Approximation with extremal processes ([1]). The length of the successive runs are independent and geometrically distributed: $\mathbf{P}\{$ length $=k\}=2^{-k}, k \geqslant 1$. The distribution of the waiting time for a head run of length at least $m$ is approximately exponential with expectation $2^{m+1}$, thus the locations of such runs is the sequence of experiments approximately form a Poisson process. Now, the model is the following: $\left(\tau_{k}, \xi_{k}\right)$ is a marked homogeneous Poisson process with intensity $\lambda=4$, and the labels $\xi_{k}$ are geometrically distributed. The length of the longest head run observed in the interval $(s, t)$ is approximately $\widetilde{Z}_{H}(s, t):=\max \left\{\xi_{k}: s<\tau_{k}<t\right\}$, which satisfies $\mathbf{P}\left\{\widetilde{Z}_{H}(s, t)<\right.$ $k\}=F(k-\lg (t-s))=F(k)^{t-s}$. Let $\Theta(t), t>0$, be the extremal process associated with $F$, that is, $\Theta(t)=\Theta(0, t)$, where the distribution function of $\Theta(s, t)$ is $F(x)^{t-s}, s<t$; $\Theta$ values over disjoint intervals are independent; $\Theta(s, u)=\Theta(s, t) \vee \Theta(t, u), s<t<u$.

Then $\Psi(t)=\Theta(t)-\lg t$ has distribution $F$, for all positive $t$. Now, $\widetilde{Z}_{H}(s, t)=$ $[\Theta(s, t)] \vee 1$, particularly, $Z_{H}(n)-N \approx \widetilde{Z}_{H}(0, n)-[\lg n]=[\Psi(n)+\{\lg n\}]$, the discretized Gumbel distribution has appeared.

The same holds for tail runs, in addition, the two marked Poisson processes can be taken independently. 
3. Differences. From (1) it is clear that the random sequence $\Delta(n)=Z_{H}(n)-$ $Z_{T}(n)$, though being stochastically bounded, does not converge in distribution in the ordinary sense. However, in [4] it is shown to have an a.s. limit distribution. Particularly, it follows that the (random) sequence of indices $n$ for which the longest head run up to $n$ is longer than the longest tail run (head leads over tail at time n, in short) does have logarithmic density with probability 1 , namely,

$$
\lim _{n \rightarrow \infty} \frac{1}{\log n} \sum_{i=1}^{n} \frac{1}{i} I(\Delta(i)>0)=2-\lg 3 \quad \text { with probability } 1 .
$$

The following problem was posed by Erdös. In how long intervals can it happen that head leads over tail all the time? Or in other words, how long 1-runs can occur in the sequence $\{$ sign $\Delta(n), n \geqslant 1\}$ ?

There are several papers dealing with runs in various dependent sequences, like in stationary $m$-dependent processes [5], or Markov chains [6]. Their results cannot be applied here, since the sequence $\{\operatorname{sign} \Delta(n), n \geqslant 1\}$ is neither Markovian, nor stationary, and it has a very long memory. As $n$ grows, the consecutive runs tend to be longer and longer.

The following result is a partial answer to Erdös's question.

Theorem. Let $f(n)$ be an increasing sequence of positive integers.

(i) Suppose $\sum(n f(n))^{-1}<\infty$. Then, with probability 1, it cannot happen that head leads over tail between $n$ and $n f(n)^{2}$.

(ii) Suppose $\sum(f(n))^{-1}=\infty$. Then, with probability 1 , head leads over tail between $f(n)^{2 n}$ and $f(n)^{2 n+2}$ for infinitely many $n$.

Particularly, it cannot happen that head leads over tail between $n$ and $n(\log n)^{2}(\log \log n)^{2+e}$, if $n$ is large enough, but head leads over tail between $n$ and $n(\log n)^{2}(\log \log \log n)^{2}$ infinitely often. Note that (2) only implies an assertion much weaker than (i): it cannot happen infinitely often that head leads over tail between $n$ and $n^{1+\varepsilon}$.

4. Essence of proof. In the approximate model with independent extremal processes $\Theta_{H}$ and $\Theta_{T}$ the probability that $\Theta_{H}\left(2^{n}\right)>\Theta_{T}\left(2^{n}\right), \Theta_{H}\left(2^{n+\delta}\right)>$ $\Theta_{T}\left(2^{n+\delta}\right), \ldots, \Theta_{H}\left(2^{n+K \delta}\right)>\Theta_{T}\left(2^{n+K \delta}\right)$ all hold, is $\frac{1}{2}\left[\left(1+2^{\delta}\right) 2^{-1-\delta}\right]^{K}$. Let $\delta=$ $(\log n)^{-2}, 2^{K \delta}=2 f^{2}\left(2^{n+1}\right)$, that is, $K \approx 2 \log ^{3} n$, then we obtain part (i).

For part (ii) consider the first $\lg f(n)$ occasions after time $f(n)^{2 n}$ when a head or tail run of extremal length ends. The probability that they are all head runs is approximately $f(n)^{-1}$, in that case head leads over tail all the time. The proof can be completed by estimating the waiting time for the last extremal run.

\section{REFERENCES}

1. Embrechts P., Klüppelberg C., Mikosch T. Modelling Extremal Events. Berlin: Springer, 1997.

2. Erdös P., Révész $P$. On the length of the longest head run. - In: Topics in Information Theory, Amsterdam: North-Holland, 1977, p. 219-228.

3. Goncharov V. L. On the field of combinatorial analysis. - Amer. Math. Soc. Transl., 1943, v. 19, p. $1-46$.

4. Móri T. F. On long runs of heads and tails. - Statis. Probab. Letters, 1993, v. 19, p. 85-89.

5. Novak S. Yu. Longest runs in a sequence of $m$-dependent random variables. -- Probab. Theory Relat. Fields, 1992, v. 91, p. 269-281.

6. Самарова C. С. О длине максимальной серии «успехов» для марковской цепи с двумя состояниями. - Теория вероятн. и ее примен., 1981, т. XXVI, в. 3, с. 510520. 
Morris K. W. (Adelaide, Australia), Szynal D. (Lublin, Poland) A goodness-offit test for the uniform distribution based on a characterization.

1. One of the simplest characterizations of a uniform distribution states that $X \sim U(0,1)$ if and only if $\mathbf{E} X^{2}=\frac{1}{3}$ and $\mathbf{E} \max \left(X_{1}, X_{2}\right)=\frac{2}{3}$, where $X_{1}$ and $X_{2}$ are independent identically distributed (i.i.d.) as $X$. This result is due to Too and Lin [2] and is a particular case of the following theorem by Lin [1].

Let $X_{k: n}$ be the $k$ th smallest order statistic of a random sample $\left(X_{1}, \ldots, X_{n}\right)$ from a distribution $F$.

Theorem (cf. [1]). Let $n \geqslant k \geqslant l+1 \geqslant 2$ be integers. Assume that $G$ is a nondecreasing and right-continuous function from $\mathbf{R} \rightarrow \mathbf{R}$. Then the relation

$$
\mathbf{E} G^{l}\left(X_{k: n}\right)=\frac{B(k+l, n-k+1)}{B(k, n-k+1)}, \quad \mathbf{E} G^{2 l}\left(X_{k-l: n-l}\right)=\frac{B(k+l, n-k+1)}{B(k-l, n-k+1)}
$$

holds if and only if $F(x)=G(x)$ on $I(F)$ (the minimal interval containing the support of $F$ ) and $F$ is continuous on $\mathbf{R}$, where $B(a, b)$ denotes the Beta function.

Letting $k=n=2$ we have the result which we use in a goodness-of-fit technique.

Corollary. $F(x)=G(x)$ on $I(F)$ and $F$ is continuous on $\mathbf{R}$ if and only if $\mathbf{E} G^{2}(X)=\frac{1}{3}$ and $\mathbf{E} G\left(X_{2: 2}\right)=\frac{2}{3}$. creasing.

2. Let $\left(X_{1}, \ldots, X_{2 n}\right)$ be a sample from $F$, where $F$ is continuous and strictly in-

Define $Y_{j}=F^{2}\left(X_{2 j-1}\right)+F^{2}\left(X_{2 j}\right), Z_{j}=F\left(\max \left(X_{2 j-1}, X_{2 j}\right)\right), j=1, \ldots, n$.

Then $Y_{1}, \ldots, Y_{n}$ are i.i.d. and $Z_{1}, \ldots, Z_{n}$ are i.i.d., and from the corollary we have $\mathbf{E} Y_{j}=\frac{2}{3}, \mathbf{E} Z_{j}=\frac{2}{3}, j=1, \ldots, n$. Writing $Y:=Y_{1}=F^{2}\left(X_{1}\right)+F^{2}\left(X_{2}\right), Z:=Z_{1}=$ $F\left(\max \left(X_{1}, X_{2}\right)\right)$ we state the following result.

Lemma. Under the above assumptions, the density function of $(Y, Z)$ is given by

$$
f(y, z)= \begin{cases}\frac{1}{\sqrt{y-z^{2}}}, & 0 \leqslant y \leqslant 2,0 \leqslant z \leqslant 1, z^{2} \leqslant y \leqslant 2 z^{2}, \\ 0, & \text { otherwise, }\end{cases}
$$

and $\mathbf{E} Y=\frac{2}{3}, \operatorname{Var}(Y)=\frac{8}{45}, \mathbf{E} Z=\frac{2}{3}, \operatorname{Var}(Z)=\frac{1}{18}, \operatorname{Cov}(Y, Z)=\frac{4}{45}$.

Now we define $\mathbf{W}_{j}=\left(\begin{array}{c}Y_{j} \\ Z_{j}\end{array}\right), j=1, \ldots, n, \mu=\mathbf{E W}_{1}, \Sigma:=\operatorname{Var}\left(\mathbf{W}_{1}\right)$, and write $\overline{\mathbf{W}}_{n}=n^{-1} \sum_{j=1}^{n} \mathbf{W}_{j}$. The CLT says that $\sqrt{n}\left(\overline{\mathbf{W}}_{n}-\mu\right) \stackrel{D}{\longrightarrow} \mathrm{V} \sim N(0, \Sigma), n \rightarrow \infty$, whence $D_{n}:=n\left(\overline{\mathbf{W}}_{n}-\mu\right)^{\prime} \Sigma^{-1}\left(\overline{\mathbf{W}}_{n}-\mu\right) \stackrel{D}{\longrightarrow} \mathbf{V}^{\prime} \Sigma^{-1} \mathbf{V} \sim \chi^{2}(2), n \rightarrow \infty$. But $D_{n}$ is a reasonable measure of the «size» of $\left(\overline{\mathbf{W}}_{n}-\mu\right)$, and so can be used to construct a test statistic of the hypothesis that $X$ has the distribution function $F$. And since $\Sigma^{-1}=45\left(\begin{array}{cc}\frac{5}{8} & -1 \\ -1 & 2\end{array}\right)$ then in extended form

$$
D_{n}=45 n\left[\left(\frac{5}{8}\right)\left(\bar{Y}_{n}-\frac{2}{3}\right)^{2}+2\left(\bar{Z}_{n}-\frac{2}{3}\right)^{2}-2\left(\bar{Y}_{n}-\frac{2}{3}\right)\left(\bar{Z}_{n}-\frac{2}{3}\right)\right]
$$
form

Letting $X_{j}^{*}=\max \left(X_{2 j-1}, X_{2 j}\right), j=1, \ldots, n$, leads, after some evaluation, to the $D_{n}=45 n\left[\frac{5}{2}\left(\overline{F^{2}\left(X_{2 n}\right)}-\frac{1}{3}\right)^{2}+2\left(\overline{F\left(X_{n}^{*}\right)}-\frac{2}{3}\right)^{2}-4\left(\overline{F^{2}\left(X_{2 n}\right)}-\frac{1}{3}\right)\left(\overline{F\left(X_{n}^{*}\right)}-\frac{2}{3}\right)\right]$, where $\overline{F^{2}\left(X_{2 n}\right)}=(2 n)^{-1} \sum_{j=1}^{2 n} F^{2}\left(X_{j}\right), \overline{F\left(X_{n}^{*}\right)}=n^{-1} \sum_{j=1}^{n} F\left(X_{j}^{*}\right)$. 
Taking into account that $X_{j}^{*}=\left(X_{2 j-1}+X_{2 j}\right) / 2+\left|X_{2 j}-X_{2 j-1}\right| / 2$, and writing $X_{j}^{o}=\left(X_{2 j-1}+X_{2 j}\right) / 2, X_{j}^{+}=\left|X_{2 j}-X_{2 j-1}\right| / 2, j=1, \ldots, n$, we obtain

$$
\begin{aligned}
D_{n}=45 n & {\left[\frac{5}{2}\left(\overline{F^{2}\left(X_{2 n}\right)}-\frac{1}{3}\right)^{2}+2\left(\overline{F\left(X_{n}^{o}+X_{n}^{+}\right)}-\frac{2}{3}\right)^{2}\right.} \\
& \left.-4\left(\overline{F^{2}\left(X_{2 n}\right)}-\frac{1}{3}\right)\left(\overline{F\left(X_{n}^{0}+X_{n}^{+}\right)}-\frac{2}{3}\right)\right] .
\end{aligned}
$$

3. If $X \sim U(0, \beta)$, i.e., $F(x)=x / \beta, x \in(0, \beta) ; \beta>0$, then

$$
\begin{aligned}
D_{n}:=D_{n}(\beta)=45 n & {\left[\frac{5}{2 \beta^{4}}\left(\bar{X}_{2 n}^{2}-\frac{\beta^{2}}{3}\right)^{2}+\frac{2}{\beta^{2}}\left(\bar{X}_{2 n}+\bar{X}_{n}^{+}-\frac{2 \beta}{3}\right)^{2}\right.} \\
& \left.-\frac{4}{\beta^{3}}\left(\bar{X}_{2 n}^{2}-\frac{\beta^{2}}{3}\right)\left(\bar{X}_{2 n}+\bar{X}_{n}^{+}-\frac{2 \beta}{3}\right)\right] .
\end{aligned}
$$

A goodness-of-fit test for $X \sim U(0, \beta)$ is given in the following proposition.

Proposition. If $\hat{\beta}_{n}=\max \left(X_{1}, \ldots, X_{2 n}\right)$, then $D_{n}\left(\hat{\beta}_{n}\right) \stackrel{D}{\longrightarrow} \chi^{2}(2), n \rightarrow \infty$.

\section{REFERENCES}

1. Lin G.D. Characterizations of continuous distributions via expected values of two functions of order statistics. - Sankhya Ser. A, 1990, v. 52, p. 84-90.

2. Too Y.H., Lin G.D. Characterizations of uniform and exponential distributions. Statist. Probab. Lett., 1989, v. 7, p. 357-359. 